\title{
Southeastern Focus Place-Based Technology Innovation Summit Report
}

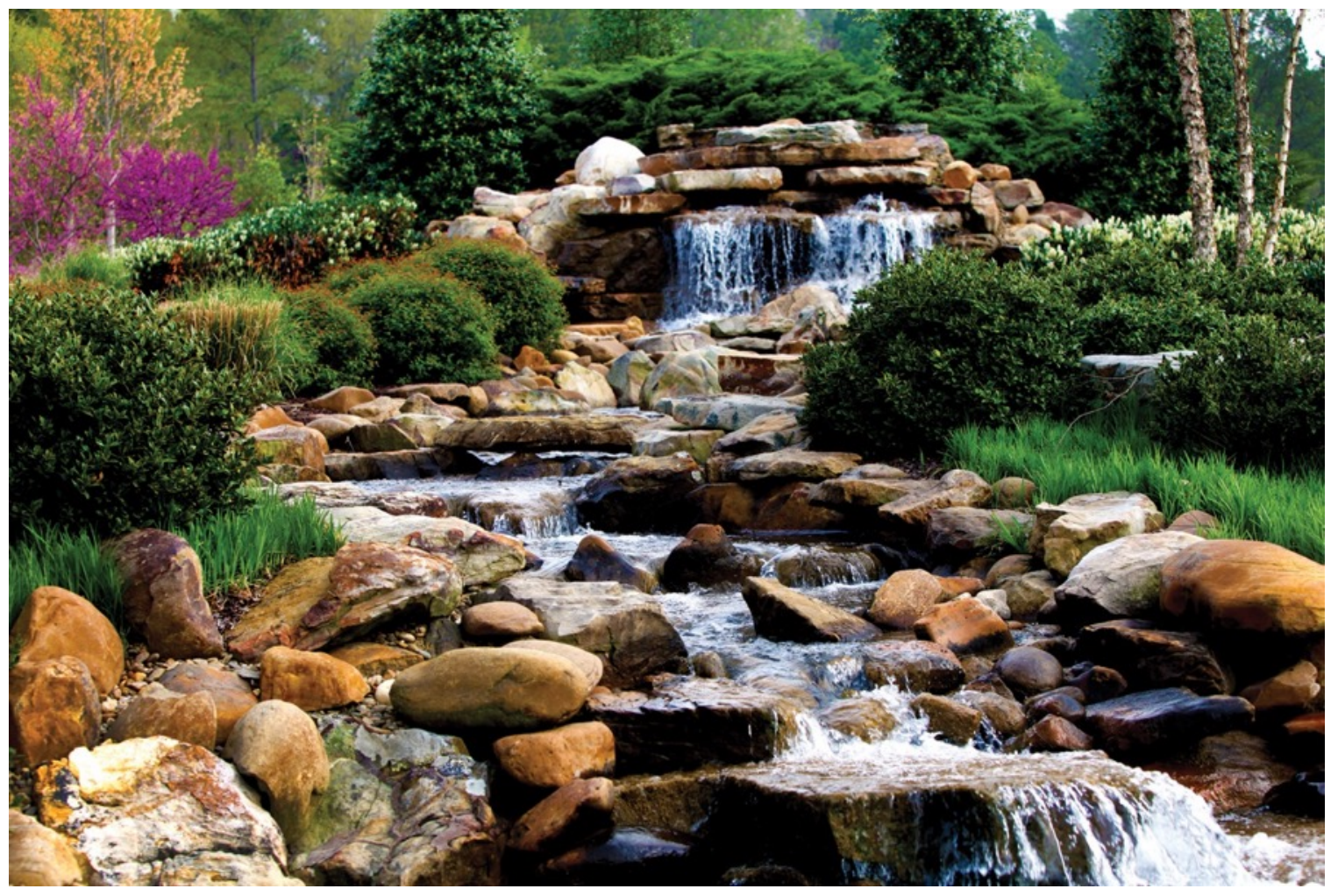

\author{
Joseph Hagerman \\ Melissa Lapsa \\ Yeonjin Bae \\ Jason DeGraw \\ Brian Fricke \\ Diana Hun \\ Piljae Im \\ Kashif Nawaz \\ Teja Kuruganti \\ Samuel Yana Motta
}

December 2021

\section{OAK RIDGE}




\section{DOCUMENT AVAILABILITY}

Reports produced after January 1, 1996, are generally available free via US Department of Energy (DOE) SciTech Connect.

Website www.osti.gov

Reports produced before January 1,1996, may be purchased by members of the public from the following source:

National Technical Information Service

5285 Port Royal Road

Springfield, VA 22161

Telephone 703-605-6000 (1-800-553-6847)

TDD 703-487-4639

Fax 703-605-6900

E-mail info@ntis.gov

Website http://classic.ntis.gov/

Reports are available to DOE employees, DOE contractors, Energy Technology Data Exchange representatives, and International Nuclear Information System representatives from the following source:

Office of Scientific and Technical Information

PO Box 62

Oak Ridge, TN 37831

Telephone 865-576-8401

Fax 865-576-5728

E-mail reports@osti.gov

Website https://www.osti.gov/

This report was prepared as an account of work sponsored by an agency of the United States Government. Neither the United States Government nor any agency thereof, nor any of their employees, makes any warranty, express or implied, or assumes any legal liability or responsibility for the accuracy, completeness, or usefulness of any information, apparatus, product, or process disclosed, or represents that its use would not infringe privately owned rights. Reference herein to any specific commercial product, process, or service by trade name, trademark, manufacturer, or otherwise, does not necessarily constitute or imply its endorsement, recommendation, or favoring by the United States Government or any agency thereof. The views and opinions of authors expressed herein do not necessarily state or reflect those of the United States Government or any agency thereof. 
ORNL/SPR-2021/2371

Buildings and Transportation Science Division, Oak Ridge National Laboratory

\title{
SOUTHEASTERN FOCUS PLACE-BASED TECHNOLOGY INNOVATION SUMMIT
} REPORT

\author{
Joseph Hagerman \\ Melissa Lapsa \\ Yeonjin Bae \\ Jason DeGraw \\ Brian Fricke \\ Diana Hun \\ Piljae Im \\ Kashif Nawaz \\ Teja Kuruganti \\ Samuel Yana Motta
}

December 2021

Prepared by

OAK RIDGE NATIONAL LABORATORY

Oak Ridge, TN 37831-6283

managed by

UT-BATTELLE LLC

for the

US DEPARTMENT OF ENERGY

under contract DE-AC05-00OR22725 


\section{CONTENTS}

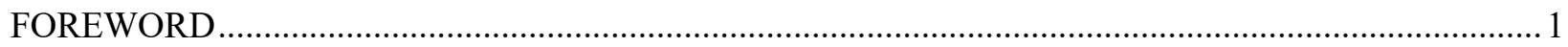

1. INTRODUCTION AND GOALS: COMMENTS FROM THE STEERING COMMITTEE.............. 1

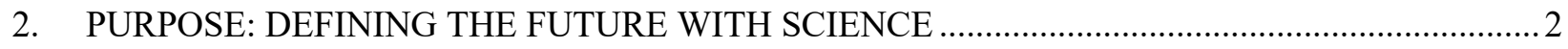

2.1 THE BEST IN SCIENCE INSPIRES PLACE-BASED INNOVATIONS .............................2

2.2 USING LOADS TO PROVIDE GRID SUPPORT CHANGES THE DYNAMICS OF CONTROL FROM A CENTRALIZED, UTILITY-OWNED ASSET TO A DECENTRALIZED, CUSTOMER-OWNED ASSET ....................................................... 3

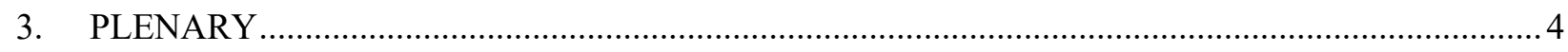

4. SESSION TOPICS: A PROCESS TO DISCUSS PLACE …......................................................... 7

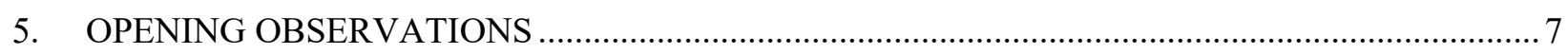

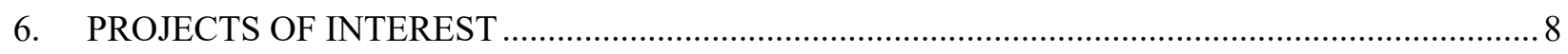

6.1 AT THE NATIONAL SCALE: CLAYTON HOMES ...................................................... 8

6.2 AT THE REGIONAL SCALE: ERWIN UTILITIES, A TVA LOCAL POWER

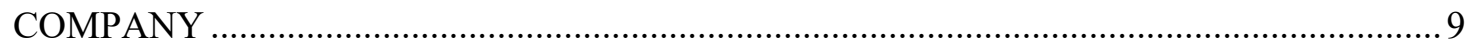

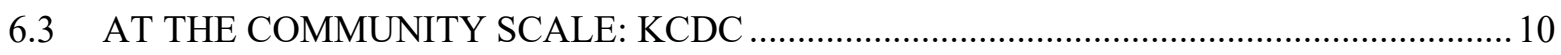

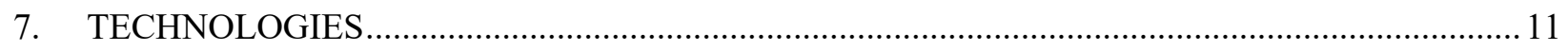

7.1 NEW, SUSTAINABLE, AND LOW-TO-NO CARBON BUILDING MATERIALS ............ 12

7.2 REEVALUATING GEOTHERMAL HEAT PUMPS FOR DECARBONIZING

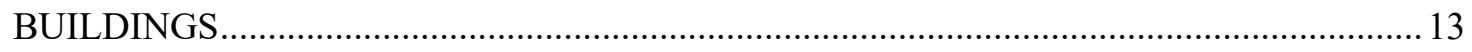

7.3 APPROACHING RETROFITS TO DECARBONIZE AND PROVIDE GRID-

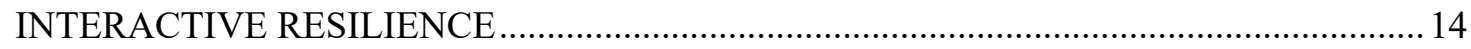

7.4 ENABLING CONNECTIVITY AND BENEFITS FROM DATA-TO-INSIGHTS ................ 15

8. BARRIERS: WHAT ARE COMMON, SHARED NEEDS OR ROADBLOCKS FOR THAT

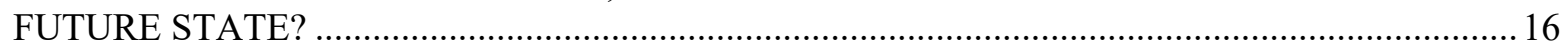

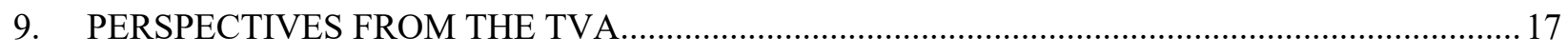

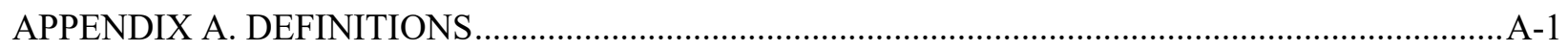

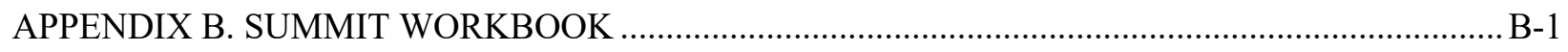




\section{FOREWORD}

Because more than $70 \%$ of the nation's current total use of electricity, 3,856 billion $\mathrm{kWh}$, is consumed by 117 million households and 5.5 million commercial buildings, ${ }^{1}$ integrating them with the grid is critical to reducing peak loads and keeping associated infrastructure costs down. Moreover, most of the load growth projected by the US Department of Energy and the US Energy Information Administration through 2040 is driven by buildings, which in turn will drive projected capacity expansions. ${ }^{2}$ Many smart grid applications are designed to minimize peak demand ${ }^{3}$ — primary among them is demand response — but as costs decrease, distributed generation and storage (both electric and thermal) may also make important contributions. Concurrently, housing is in high demand after years of underinvestment in new housing starts. $^{4}$

\section{INTRODUCTION AND GOALS: COMMENTS FROM THE STEERING COMMITTEE}

This meeting focused on taking science-based action to realize decarbonized, place-based, clean energy interventions that are equally shaped by, inspired from, and committed to the communities they serve. We seek to make clean energy technologies applicable, relevant, and significant for all communities throughout the various scales of place - from Knoxville, Tennessee, to the Tennessee Valley Region, to the entire Southeast. This meeting matched researchers with community groups and businesses that are creating change in the built environment.

The outcomes of this meeting were clear decisions, action plans to effect change, and connections to those that can augment, leverage, and otherwise make a real contribution to the communities, neighborhoods, and households that define us as a region.

"The opportunities before the nation are great: vastly expand the number of homes, customers, and types of end-uses engaged and the range of grid benefits derived by utilizing the smart grid's communication technologies to signal customers and connected appliances, equipment, and devices. And future solutions will take science-based advancements and new technologies."

—Dr. Xin Sun, Welcome Letter

Definitions were provided to participants (see Appendix A: Definitions). A connected community is a group of grid-interactive efficient buildings with diverse, flexible end-use equipment that collectively works to maximize building, community, and grid efficiency without compromising occupant needs and comfort. Southern Company and Oak Ridge National Laboratory (ORNL) pioneered connected communities in our Smart Neighborhood activities between 2015 and 2017. Connected communities are smart communities in the sense that the collection of homes can work together and have a community connection to the utility. The community can control the gross shape of its load, and the houses can determine how to achieve their own internal goals without service disruptions. Therefore, the homes must transact by sharing information or actions with one another to achieve the community goal.

\footnotetext{
${ }^{1}$ DOE/EIA estimate from 2011, see http://www.eia.gov/energyexplained/index.cfm?page=electricity use.

2 DOE/EIA, Annual Energy Outlook 2013, see Tables 2 and 9, http://www.eia.gov/oiaf/aeo/tablebrowser/\#release=AEO2013\&subject=0-AEO2013\&table=2-AEO2013\&region=1-

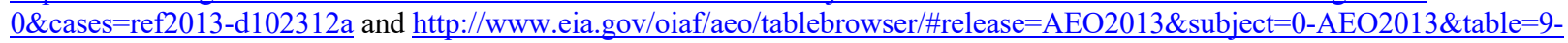
AEO2013\&region $=0-0 \&$ cases $=$ ref2013-d102312a.

${ }^{3}$ EIA data on peak demand, see http://www.eia.gov/tools/faqs/faq.cfm?id=100\&t=3.

${ }^{4}$ See https://cdn.nar.realtor/sites/default/files/documents/Housing-is-Critical-Infrastructure-Social-and-Economic-Benefits-ofBuilding-More-Housing-6-15-2021.pdf.
} 
"Science must be inclusive, diverse, and meaningful to all communities and all familiesit is our responsibility as a national laboratory to make this possible."

—Dr. Xin Sun, Welcome Letter

\section{PURPOSE: DEFINING THE FUTURE WITH SCIENCE}

We are at the forefront of change, and this summit helped define the future state that we collectively hope to achieve. The future grid - and the homes, communities, and families that it powers - will provide a seamless, cost-effective electricity system from generation to end-use with the flexibility to accommodate all clean energy sources and capacity requirements.

The challenge of addressing variable resources is part of a larger grid-modernization agenda that must address many other profound changes in the nation's infrastructure, such as consideration of how best to use natural gas, increased consideration of distributed generation, limited ability to expand the transmission system, and measures to add flexibility to the system, including energy storage. Most importantly, it must consider place.

These issues, or rather opportunities, motivate ORNL. In the future, a significant scale-up of clean energy, universal access to consumer participation and choice, holistically designed solutions, two-way flows of energy and information, reliability, security, and resiliency will be necessary. However, this future system can be successful only if our sciences find a place in everyday life. The practical application of science guided this summit and ORNL's focus on thoughtful, meaningful place-based research.

\subsection{THE BEST IN SCIENCE INSPIRES PLACE-BASED INNOVATIONS}

This summit allowed ORNL researchers to collaborate and connect with industry and communities that are transitioning to a clean-energy economy. ORNL designs, develops, tests, and validates distributed sensing and control agents, algorithms, and software tools to deliver cost-effective and scalable solutions that enable deep building to grid integration. This work enables buildings to supply, consume, regulate, and store energy by using controls. These control solutions are achieved with the following approaches:

- A scalable agent-based distributed sensing and controls platform to deliver cost-effective, cybersecure, open-source, and scalable solutions

- Distributed software agents that can make autonomous and collective decisions to achieve optimum solutions (e.g., minimizing energy or cost, maximizing efficiency or grid reliability, and minimizing emissions)

- Highly automated software applications and tools to solve nonlinear and complex controls in buildings

- Machine learning agents and applications that are adaptive, self-configuring, and self-correcting

- Agents and applications that rely on probability theory to manage risk under uncertainty while making optimal decisions 


\subsection{USING LOADS TO PROVIDE GRID SUPPORT CHANGES THE DYNAMICS OF CONTROL FROM A CENTRALIZED, UTILITY-OWNED ASSET TO A DECENTRALIZED, CUSTOMER-OWNED ASSET}

This change requires new distributed control formulations, entities, and considerations. To meet reliability requirements, these formulations must be constructed to demonstrate mathematical stability, optimality, and robustness before being deployed in the electric grid. These considerations shape the ORNL Building Technologies Program's (BTP's) flexibility vision, mission, and goals.

\section{ORNL BTP Flexibility Vision}

In the future, the science will be known to increase, enhance, or affect flexibility in buildingrelated systems (e.g., equipment, buildings, neighborhoods, communities) at the various interrelated scales at which the systems and their subsystems operate.

\section{ORNL BTP Flexibility Mission}

This future state requires new areas of science to explore flexibility from the various perspectives of materials, component level (e.g., equipment and envelope), control systems (e.g., individual, whole facility), whole buildings, and whole portfolios of assets/loads, whether they are behind the meter, across the meter, or at the meter for leverage by the utility.

\section{ORNL BTP Flexibility Goals}

These capabilities should simultaneously decrease the burden and cost of grid modernization while providing consumers and other energy service providers with new opportunities to connect, either in partnership with their utility or to otherwise engage with the larger electricity markets.

Once realized, ORNL's research goals will allow buildings, owners, and operators to have flexibility with data-driven solutions at scale with enhanced consumer, utility, and societal benefits. Compared with other storage solutions, these solutions are cost effective and offer competitive round-trip efficiency.

ORNL's flexibility research addresses core scientific questions. Fundamentally, flexibility is a domestic resource that has the capacity to expand American jobs if communities value that flexibility. Research findings could serve as recommendations to policy makers and government entities involved in shaping future energy systems so that buildings are an asset within the system rather than merely a user of the system. This research enhances the capacity of distribution utilities to add renewable energy, distributed energy resources, energy efficiency, or new technologies that are not widely adopted today. In prior work, the US Department of Energy (DOE) stated that the potential value of continuously engaging real-time flexible loads in both residential and commercial buildings to provide grid services, if deployed at the national scale, is $\$ 22$ billion ("The National Opportunity for Interoperability and its Benefits for a Reliable, Robust, and Future Grid Realized Through Buildings," US Department of Energy, 2016).

ORNL's research is significant and can provide options in the future. Flexible buildings can mitigate the costs and effects of grid modernization. Simply put, the current energy system does not take full advantage of the United States' 5.6 million commercial buildings and 120 million households, which leaves billions of dollars in efficiency, energy, and infrastructure savings untapped. 
Enabling flexibility in buildings could allow utilities to improve their resilience. The regulatory commissions define three key indices of a utility's resilience.

(1) The System Average Interruption Duration Index (SAIDI) measures the number of interruptions per consumer per year:

$$
\text { SAIDI }=\frac{\text { number of interruptions }}{\text { total customers } / \text { year }}
$$

(2) The System Average Interruption Frequency Index (SAIFI) measures the average time of interruptions per consumer per year:

$$
\mathrm{SAIFI}=\frac{\text { duration of interruptions in minutes }}{\text { total customers } / \text { year }}
$$

(3) The Consumer Average Interruption Duration Index (CAIDI) measures the average interruption time per consumer affected by the interruption per year:

$$
\mathrm{CAIDI}=\frac{\text { duration of interruptions in minutes }}{\text { affected } \text { customers } / \text { year }}
$$

A decrease in these indices reflects an increase in a utility's reliability and resilience response.

This work provides storage options that may not be as expensive as buying whole-house battery systems and integrating them with buildings or other consumers of the grid. It also provides non-wired options to help meet environmental or emissions goals.

ORNL's research helps the broader market by raising awareness of the flexibility opportunity for the entire energy system and providing an opportunity to increase industry and academic readiness to scale flexibility. Working with partners, ORNL maps the barriers to, motivations for, and acceptance of energy flexibility measures in buildings and clusters of buildings as a grid asset once interoperability and other foundational issues are addressed. ORNL accomplishes this mapping by defining project requirements and use, value, and business cases of each solution under investigation.

\section{PLENARY}

Since 1943, ORNL has been a leader in using science to advance place-based, impactful results. Today, ORNL can have an outsized impact on underserved and transitioning communities.

ORNL is "solving today's social and economic problems with tomorrow's technology."

—Alvin Weinberg, Oak Ridge National Laboratory: The First Fifty Years 

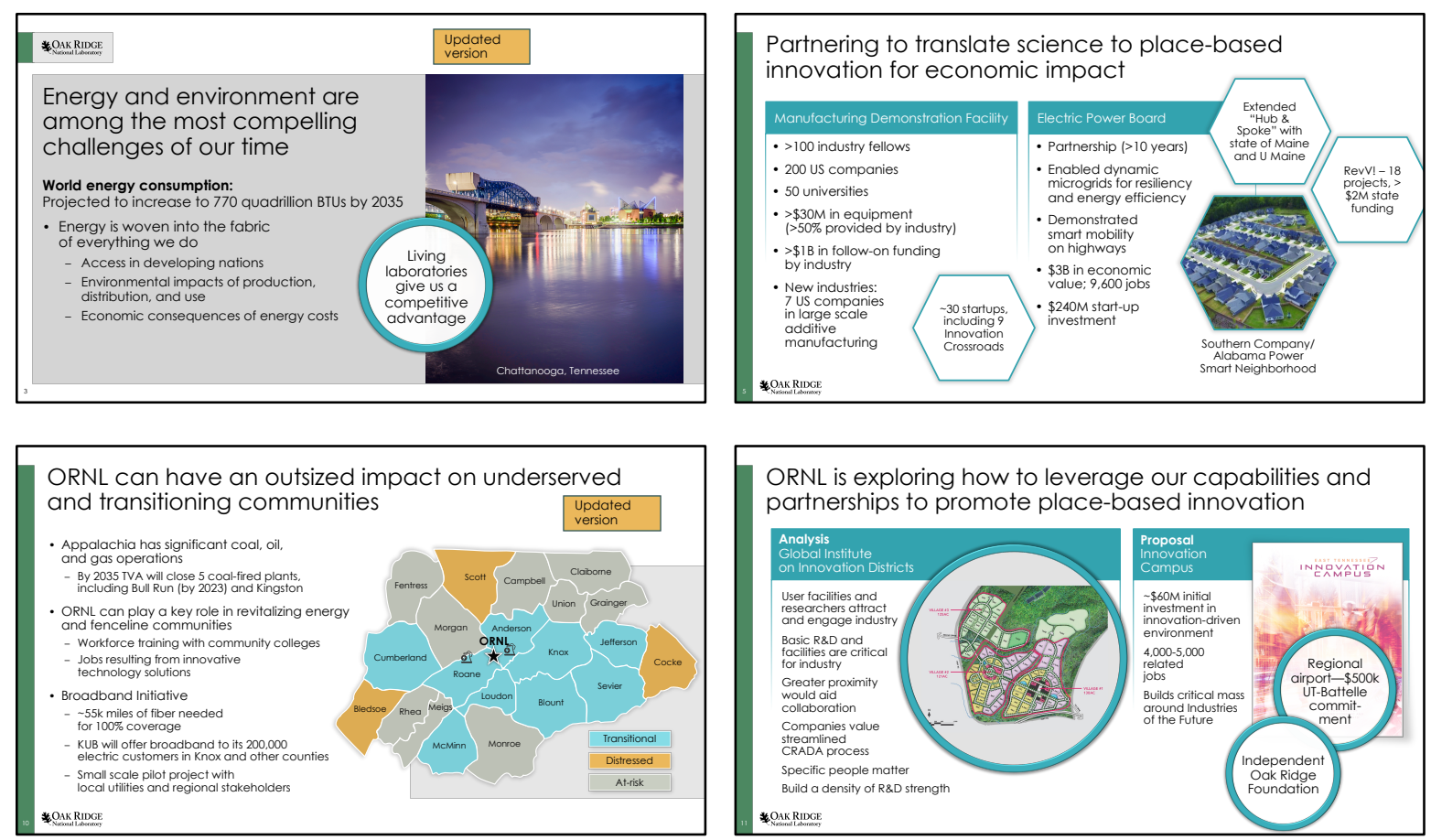

Figure 1. Slides from Dr. Moe Khaleel's (ORNL's deputy laboratory director) presentation.

ORNL sits on the border of two East Tennessee counties: Anderson County and Roane County. These counties are ranked 1,594 and 1,764, respectively, out of the nation's 3,113 underserved counties. The labor shed that supports the Oak Ridge Reservation consists of 21 Tennessee counties: Anderson, Bledsoe, Blount, Campbell, Claiborne, Cocke, Cumberland, Fentress, Grainger, Jefferson, Knox, Loudon, McMinn, Meigs, Monroe, Morgan, Rhea, Roane, Scott, Sevier, and Union. Three of these counties are designated as distressed, nine are designated as at risk economically, and nine are designated as transitional economies. ${ }^{5}$ These 21 counties have a population of almost 1.4 million, with about $23 \%$ living in distressed and at-risk counties economically.

ORNL is exploring its role in defining innovation districts: economic development-based centers that have emerged around growing and livable city landscapes and are supported by the areas' R\&D, industrial, and academic assets.
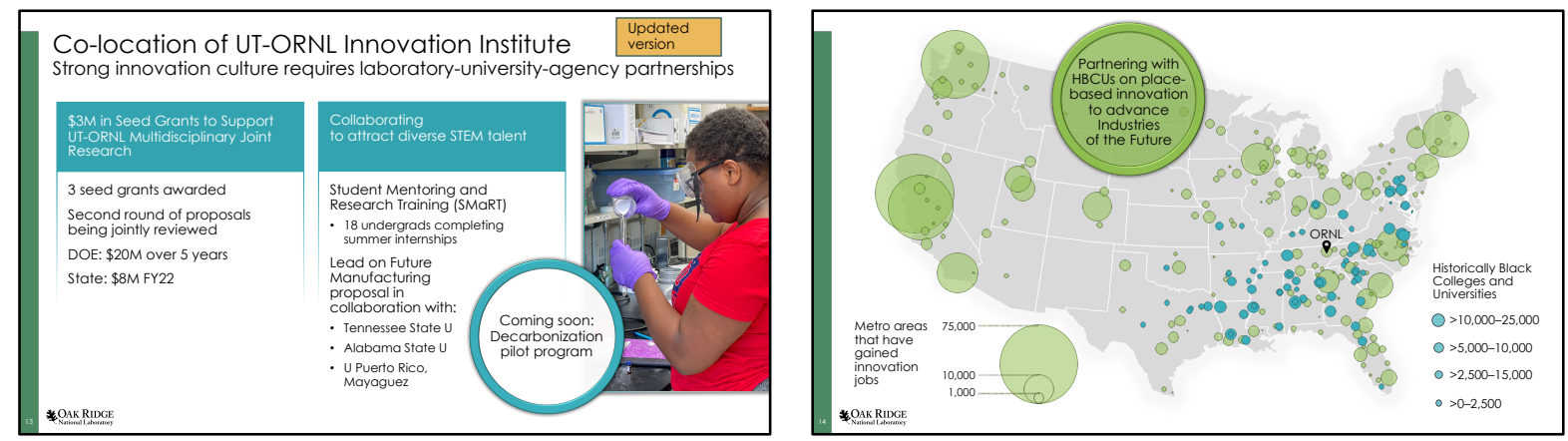

Figure 2. Slides from Dr. Moe Khaleel's (ORNL's deputy laboratory director) presentation.

\footnotetext{
${ }^{5}$ https://www.arc.gov/wp-content/uploads/2020/07/CountyEconomicStatusandDistressAreasFY2021Tennessee.pdf
} 
Oak Ridge is only about 25 miles from the University of Tennessee's (UT's) flagship campus in Knoxville, and the two institutions have worked together since ORNL's earliest days when several UT faculty members joined the Manhattan Project efforts in Oak Ridge. About 130 UT graduate students are currently assigned to ORNL research projects through the Bredesen Center for Interdisciplinary Research and Graduate Education or the UT-ORNL Graduate School of Genome Science and Technology (GST). UT and ORNL have created the University of Tennessee Oak Ridge Innovation Institute to integrate all joint programs, including faculty, institutes, Governor's Chairs, the Bredesen Center, and the Graduate School of GST. Students receive professional development training, including communications, computational literacy, and technology transfer, to prepare them for the $21^{\text {st }}$ century workforce and develop their entrepreneurial skills.
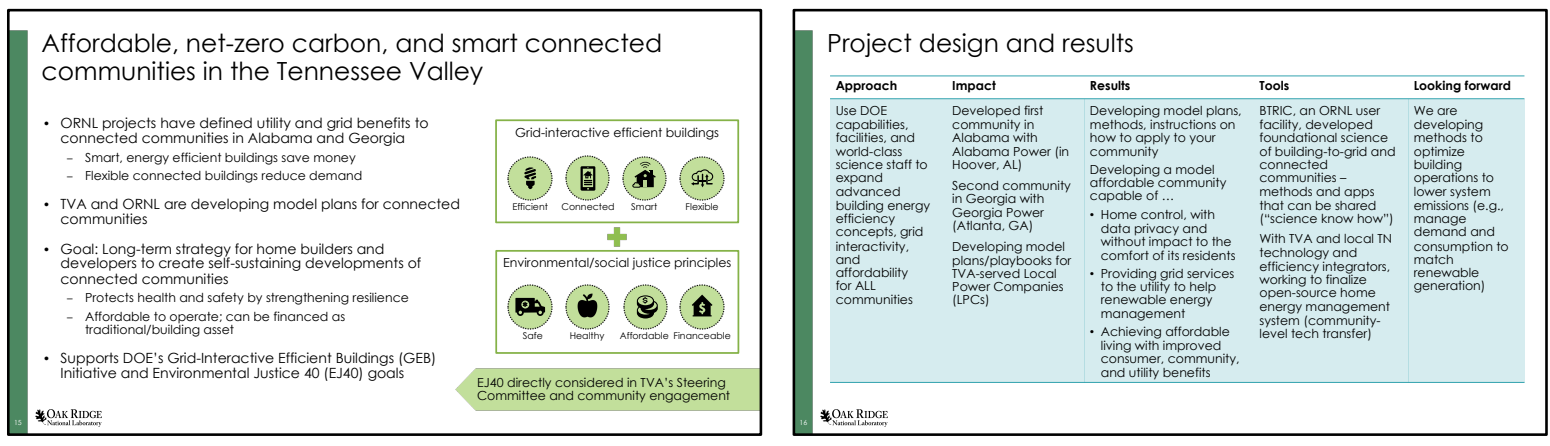

Figure 3. Slides from Dr. Moe Khaleel's (ORNL's deputy laboratory director) presentation.

DOE laboratories can respond and make significant contributions to place-based innovation by sharing best practices and lessons learned. DOE laboratories can help define flexible goals by bringing people and communities together with local utilities to address specific challenges, including energy efficiency, grid interactivity, affordable housing, and neighborhoods. However, DOE systems require agility to move at the pace of the partners (including utilities and builders) to see action. ORNL themes include the following:

- Ensuring technology access for all to emphasize that new clean energy technologies are for all people, all regions, and all socioeconomic groups and

- Ensuring renewable access for all to emphasize that new clean energy sources, such as solar or wind, should benefit all communities and socioeconomic groups.

A place-based systems science approach must

- align to local issues and aspirations - often making good on long-held community goals — while being aligned with national sustainability goals;

- address regional disparities and demonstrate awareness of social infrastructures;

- harness data sharing to promote access to information;

- create shared visions for communities and regions;

- coordinate delivery, probing, and learning through the various scales of engagement; and

- give due attention to all relevant perspectives, parties, and community groups. 


\section{SESSION TOPICS: A PROCESS TO DISCUSS PLACE}

Session 1 involved goal setting to lead innovation. This session focused on defining goals for placebased success and proposed strategies to achieve it. This discussion helped define the end state of success for the groups and shaped and altered that vision given the needs to support the best science, include all people and thoughts, and promote change. Working in groups, participants discussed their current ideas about advanced communities, buildings, and programs that will change place and energy use. Setting goals is important to understanding our targets and the value of the change to customers, community members, and families.

Session 2 involved technology innovators leading the future. This session was a roundtable on innovative, affordable, energy-efficient, and low-embodied carbon technologies (e.g., heat pumps, multifunctional equipment, active envelope systems, and controls for grid-interactive buildings) for communities in the Southeast. Working in groups and with technology experts as consultants, participants selected the technology group that interested them and discussed how it should be applied, its ability to help achieve goals, and the positives and negatives of the technologies.

Session 3 involved an open discussion on how we can overcome today's challenges to lead into tomorrow. This session identified common barriers and opportunities to overcome those impediments.

\section{OPENING OBSERVATIONS}

Clayton Homes aims to be a world-class producer of the best, most advanced homes for all. The Clayton Homes group discussed the value proposition for Clayton Homes, which produces an estimated 50,000 homes per year. They seek information in developing renewable and net zero-ready homes; prefabricated connected-ready homes with broadband connections pre-wired; and shared services in which the real estate developers understand the value proposition of making these communities utility and demandresponse friendly.

Knoxville's Community Development Corporation (KCDC) seeks to be a model for the community and nation in decarbonization focused on community development innovation. Given that KCDC manages 4,000 publicly owned units with water and electricity subsidized, they must align goals across funding and energy agencies. Overall, more education is necessary regarding options, funding opportunities, and technical leadership engagement to help identify high-return-on-investment ideas (with clear metrics and value) and scale them up across the Southeast.

Erwin Utilities Association is a Tennessee Valley Authority (TVA) local power company that represents small municipal-scaled utilities seeking to build and support communities of the future. Erwin Utilities Association is interested in connecting more people to achieve their vision of a connected community. The city of Erwin, Tennessee, must overcome the barriers of inefficient homes, mobile homes, and rental properties with high energy bills. Previously, the Home Uplift program from TVA had low participation because community engagement, home ownership, and landlord participation were required. Participation could be increased if residents want their homes to be more energy efficient, but retrofits and retrofit funding are always an issue.

The City of Knoxville acts as a TVA power company through the city's independent Knoxville Utility Board and represents large municipal-scale city utilities seeking to build and support communities of the future. The City of Knoxville knows the barriers for most technologies and must define its goals and the technologies to achieve those goals. TVA funding is a great opportunity to support field demonstrations. 
The City of Knoxville must establish partnerships based on funding sources and likelihood of influence and outcome(s).

ORNL invited The Great Smoky Mountains Institute at Tremont (Tremont Institute), a place-based educational facility, to the summit as a special guest. "People's personal experiences with nature may work better than dire warnings to motivate environmental action ... This means interaction with local species in science classes and outdoor experiences may build lifelong awareness, concern, and actions for the environment." Tremont Institute has an opportunity to influence young minds through "footprints and handprints" in nature. How does the institute's place in the community benefit the area and participants? A demonstration of the Living Building Challenge can positively affect place. Water (decentralized treatment and rainwater) and energy (battery storage, connected buildings, and occupant behaviors) can yield healthier and happier places (happy indoor environment, indoor air quality, access to nature) and equity (healthy access, accessible and resilient trails, workforce development-trained heat pump installers, and positive environmental impact education).

One common observation was made at the beginning of the meeting: DOE may be well served if they helped the industry establish common, clear, and concise definitions. Therefore, definitions are listed in Appendix A.

\section{PROJECTS OF INTEREST}

\subsection{AT THE NATIONAL SCALE: CLAYTON HOMES}

Clayton Homes is the largest single builder of manufactured and modular homes in the United States. Clayton's subsidiaries complement their leadership in the housing sector, including the nation's largest manufactured home lender, Vanderbilt Mortgage/21st Mortgage, and the Home First Agency home insurance company. Clayton believes a smart, connected manufactured home (MH) solution - one that is affordable, safe, healthy, and beneficial to the consumer's bottom line-can challenge the long-held negative stereotypes that the manufactured home sector faces. Smart, connected neighborhoods could use technology to extend the benefits to residents of all income levels. Energy savings has a much larger impact for homeowners in the MH industry (American Council for an Energy-Efficient Economy). Ultimately, Clayton must establish a replicable framework for constructing affordable, smart housing that has clear value to consumers and utilities.

Clayton's goal is to support connected communities from production to service. Clayton needs to focus on the production side (e.g., looking at manufacturing processes) to address production challenges to achieve any decarbonization goals. Clayton's interests include

- decarbonization solutions and how they can apply to underserved communities,

- a replicable business model in which Clayton as a housing company can understand the utility market changes, and

- developing solutions that can benefit homeowners and utility companies.

Clayton understands the importance of community ownership in common, connected services that could be placed into the homeowners' association interests and must also understand the challenges of shared service (e.g., education, management, and relationship to the buy/seller/customer).

\footnotetext{
${ }^{6}$ https://news.umich.edu/environmental-actions-are-motivated-by-personal-experiences/
} 
To enable connected communities, Clayton may focus on educating buyers and sales distribution channels. Clayton discussed the importance of educating consumers because the solution that is most appealing to customers may not be fully optimized or considered in the whole smart home strategy. Clayton must understand what value comes from advanced technology and to whom the value accrues so they can sell those values to other entities beyond the homeowner.

Clayton seeks to provide continuity of energy efficient technology/service to connected communities. Clayton also hopes to collaborate with utility services. For example, Clayton would need to reliably communicate with a home's water heater, and Clayton may need to develop community infrastructure. In community real estate developments, shared services are possible, and connecting back to the utility company is a good idea; however, technical difficulties may impede the quality and reliability of the services offered back to the utility.

Taking ACTION: Since the start of ORNL's Southeastern Place-Based Innovation Summit, Clayton has optioned properties around their headquarters to explore the development of a connected community to understand how it may be developed as a business model for their business and customers.

\subsection{AT THE REGIONAL SCALE: ERWIN UTILITIES, A TVA LOCAL POWER COMPANY}

Incorporated in 1945, Erwin Utilities provides electric, water, and wastewater services, along with fiberoptic services through Erwin Fiber, throughout Unicoi County, Tennessee. In partnership with TVA, the nation's largest public power producer and a corporate agency of the federal government, the city-owned utility provides electricity to more than 8,850 business and residential end-use customers and maintains more than 260 miles of electric distribution and fiber line.

Erwin's history is also closely tied to DOE. The city's largest employer, Nuclear Fuel Services, has close ties to DOE and the US Navy. Nuclear Fuel Services' facility began operation in 1957. Production activities at the Erwin facility include preparation of enriched uranium for processing into nuclear reactor fuel, processing uranium hexafluoride into other uranium compounds, and down-blending high-enriched uranium for conversion to a low-enriched form for use in commercial nuclear reactors. Following the National Nuclear Security Administration's recent award of a \$57.5 million Phase 1 contract to Nuclear Fuel Services for the design and pilot demonstration of highly enriched uranium conversion and purification services, Erwin seeks to help Nuclear Fuel Services and other employers attract talent by offering advanced residential technologies not typically found in other small, rural communities.

To achieve this goal, Erwin is exploring connected communities as an innovative concept to help attract and retain diverse talents to meet the city's needs. Erwin, with TVA, is exploring utility programs that validate scalable and reliable deployment of commercially available distributed energy resources in a rural community with widely available broadband access. Erwin Utilities' advanced metering infrastructure and secure overlay network architecture from Erwin Fiber can enable utility operations to have two-way connectivity to distributed energy resources and load profiles. Additionally, Erwin can utilize device data to establish baseline performance, determine load flexibility, and enable online control and dispatch decision-making. Erwin seeks to help grid health, reliability, and resilience at the bulk system level, with TVA as the wholesale electricity provider, and at the distribution level. Intended grid outcomes include peak demand reduction, voltage support, renewable-responsive load shapes, and transmission peak/congestion reduction. Erwin has two goals:

1. Provide valuable grid benefits that may help all customers via temporally and spatially coordinated responses from several assets, given the magnitude or capacity of the assets 
2. Develop an end-to-end system for engaging residential distributed energy resources and customer loads so that these loads can be used as resources to provide grid service when and where the distribution utility needs them

Taking ACTION: Since the start of ORNL's Southeastern Place-Based Innovation Summit, TVA has funded the development of control architecture to allow utilities such as Erwin Utilities to exercise behind (or at) the meter distributed energy resources for consumer and utility benefits.

\subsection{AT THE COMMUNITY SCALE: KCDC}

KCDC is the public housing authority for Knoxville and Knox County. KCDC manages and rents more than 3,700 units across more than 20 properties and manages the application process and distribution of 4,000 Section 8 vouchers. KCDC also serves as the redevelopment agency for the City of Knoxville and fosters economic development by approving tax credits and incentives for new businesses in the area. KCDC operates residential properties for Knoxville's low-income residents. Many of these properties are aging and have relatively high energy costs. In comparison with households at other income levels, lowincome households generally spend a larger percentage of their total income on home energy costs and have less comfortable living spaces.

Leveraging ORNL's capabilities, KCDC hopes to conduct a deeper investigation of ways to minimize energy use in these properties and improve the thermal comfort of residents that use technologies. The following list contains next steps.

- The Tennessee Department of Environment and Conservation suggests that KCDC provide ORNL with detailed KUB data for analysis of peak energy demand charges and strategies for lowering energy costs paid on behalf of low-income residents.

- $\quad \mathrm{ACE}$ IoT Solutions is interested in partnering with $\mathrm{KCDC}$ and $75 \mathrm{~F}$ to evaluate packaged terminal air conditioner units and using the VOLTTRON platform to reduce peak energy demand paid on behalf of low-income residents.

- An ORNL team may visit KCDC and tour new construction sites and existing infrastructure rehabilitations, including high-rise renovations.

- A KCDC team may visit an ORNL project house for inspiration on other areas to consider for largescale improvements.

- $\quad$ KCDC is reviewing TVA Connected Communities Call for Pilots and is in the process of narrowing down the field of project ideas. KCDC learned about this call for pilots at the conference.

- Pilot \#1 idea: provide free internet in public areas and public parks on KCDC properties.

- Pilot \#2 idea: connect KCDC with the City Transforming Western project, which involves bringing community partners together to provide onsite job training, workforce development, and innovation. KCDC has reached out to Bill Peter, director of the Manufacturing Demonstration Facility, about a possible partnership.

- Pilot \#3 idea: evaluate KCDC packaged terminal air conditioner units with ACE IoT Solutions as lead. 
Taking ACTION: Since the start of ORNL's Southeastern Place-Based Innovation Summit, TVA has funded the development of Home Energy Management Systems development, including customer engagement, to understand how these diverse technologies in buildings can provide consumer, utility, and manufacturer value.

\section{TECHNOLOGIES}

DOE's Building Technologies Research and Integration Center (BTRIC) at ORNL became operational in 1991. In 1993, DOE's Office of Energy Efficiency and Renewable Energy designated BTRIC as a user facility to provide unique research capabilities for energy efficient buildings research in collaboration with industry, academia, associations, and other national laboratories. Today, BTRIC remains DOE's only national user facility dedicated to buildings energy efficiency. Furthermore, BTRIC offers a gateway to core capabilities at ORNL, including materials, neutrons, advanced manufacturing, and highperformance computing. BTRIC addresses the need for unique state-of-the-art facilities, capabilities, and expertise to help discover, develop, evaluate, and accelerate innovative energy-efficient building technology solutions.

ORNL has more than 40 years of R\&D leadership in building technologies and has earned the respect of government agencies, industry, and universities in the United States and abroad. BTRIC staff have the proven ability to bridge the gap between basic science and early-stage applied R\&D. They can couple that earlystage applied $R \& D$ to industry for later-stage $R \& D$ and implementation, which introduces many industry partner products to the market, thereby yielding economic improvement and job creation. BTRIC is composed of an unparalleled collection of buildingsrelated experimental facilities encompassing more than $38,000 \mathrm{ft}^{2}$ of laboratory space. The broad collection of unique capabilities includes technology areas for residential and commercial buildings, such as wireless sensors and transactive controls (buildings-to-grid), advanced energy storage, HVAC, envelopes, building energy modeling, and whole-building and systems integration. These areas address all the needs for gridinteractive efficient buildings. BTRIC focuses on the following:
Equipment R\&D focus areas

- Vapor compression cycles (including trans-critical, ejector, and other variations)

- Absorption/adsorption/desiccant cycles

- Magnetocaloric/electrocaloric cycles

- Working fluids, materials

- Heat pumps, air conditioners, dehumidifiers

- Packaged rooftop units

- Appliances

- Water heaters

- Supermarket refrigeration systems

- Ground-source space conditioning and water heating systems

- Multizone HVAC systems

- Wireless communications, sensors, controls, fault detection, and diagnostics

- Equipment platform. Indoor amenities that improve consumer health and productivity (e.g., heating, cooling, hot water, and refrigeration) can accomplish their purpose while consuming less energy by using operational efficiency advancements in building equipment components. 
- Building systems development and integration platform. BTRIC's residential and light commercial building test beds impose natural weather exposure and an average occupant effect on energy use to provide realistic loads, operating conditions, and interactive and transactive effects for technology evaluation and physical validation of models. Harnessing the energy usage of residential and commercial buildings with these precise controls can manage building energy usage and balance critical operation of the national power grid system. The facilities and expertise in BTRIC address renewable energy and grid-interactive efficient building challenges, including data management and cybersecurity.

- Envelope Platform. To cost-effectively improve the energy efficiency, moisture durability, and environmental sustainability of building envelopes, this platform explores new and emerging materials, components, and systems, as well as the fundamentals of heat, air, and moisture transfer.
Building systems development and integration $R \& D$ focus areas

- Residential and light commercial building flexible research platforms

- Computer modeling, visualization, analytics

- Whole building performance and transactive controls

- Building sensors and power electronics

- Building cybersecurity

Envelope $R \& D$ focus areas

- Walls

- Roofs and attics

- Foundations

- Sheathings

- Membranes

- Coatings

- Materials

\subsection{NEW, SUSTAINABLE, AND LOW-TO-NO CARBON BUILDING MATERIALS}
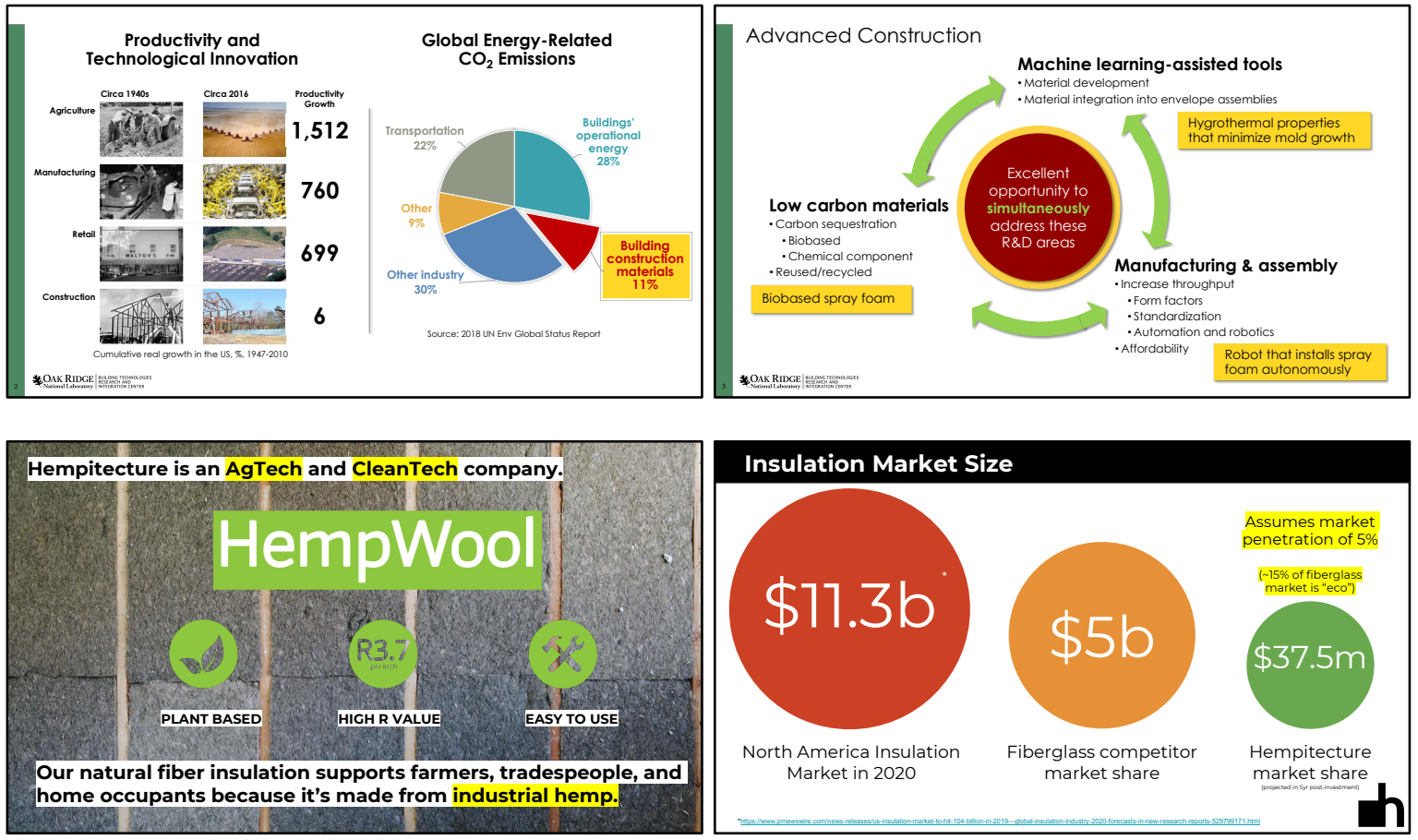

Figure. 4. Slides from Tommy Gibbons' (Hempitecture) presentation. 


\subsection{REEVALUATING GEOTHERMAL HEAT PUMPS FOR DECARBONIZING BUILDINGS}

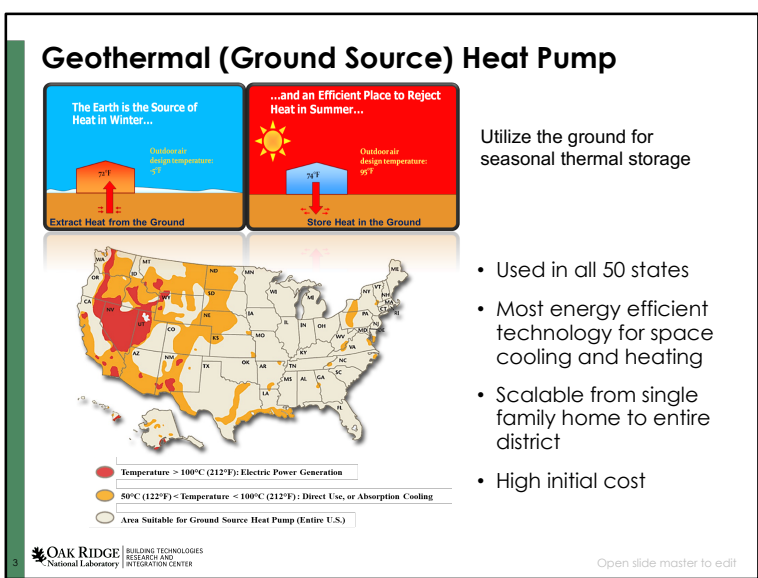

New Development for Reducing Cost
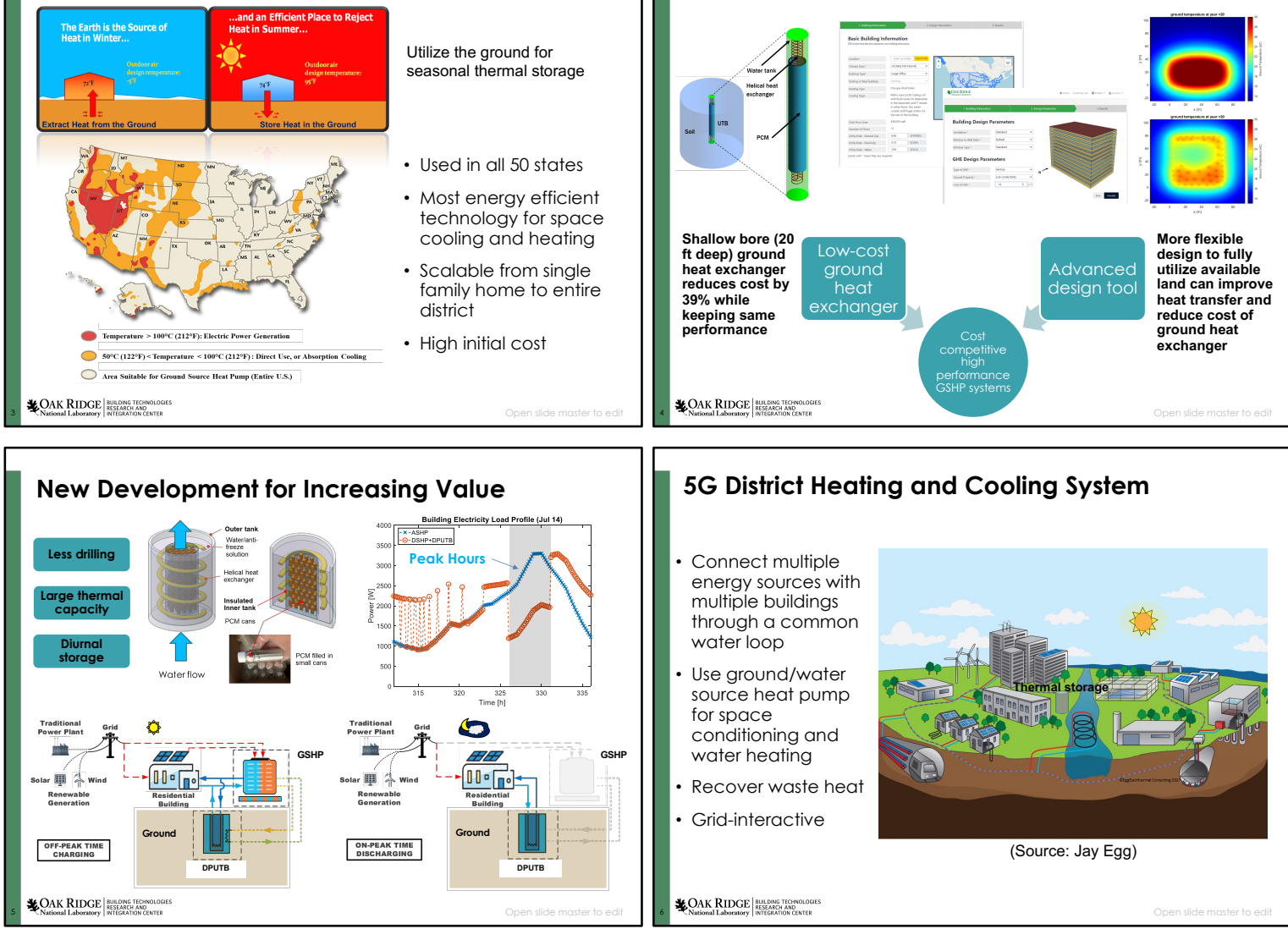

5G District Heating and Cooling System

- Connect multiple energy sources with multiple buildings through a common water loop

- Use ground/water source heat pump for space conditioning and water heating

- Recover waste heat

- Grid-interactive

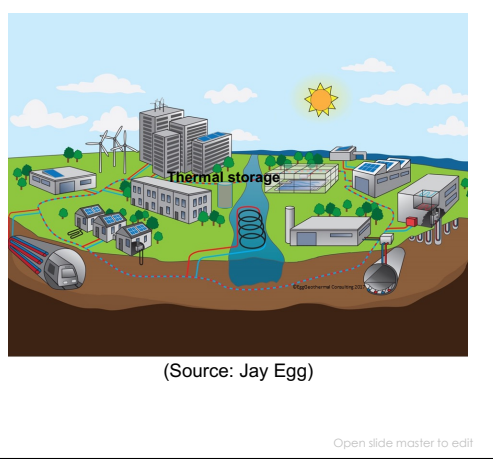

* OAK RIDGE
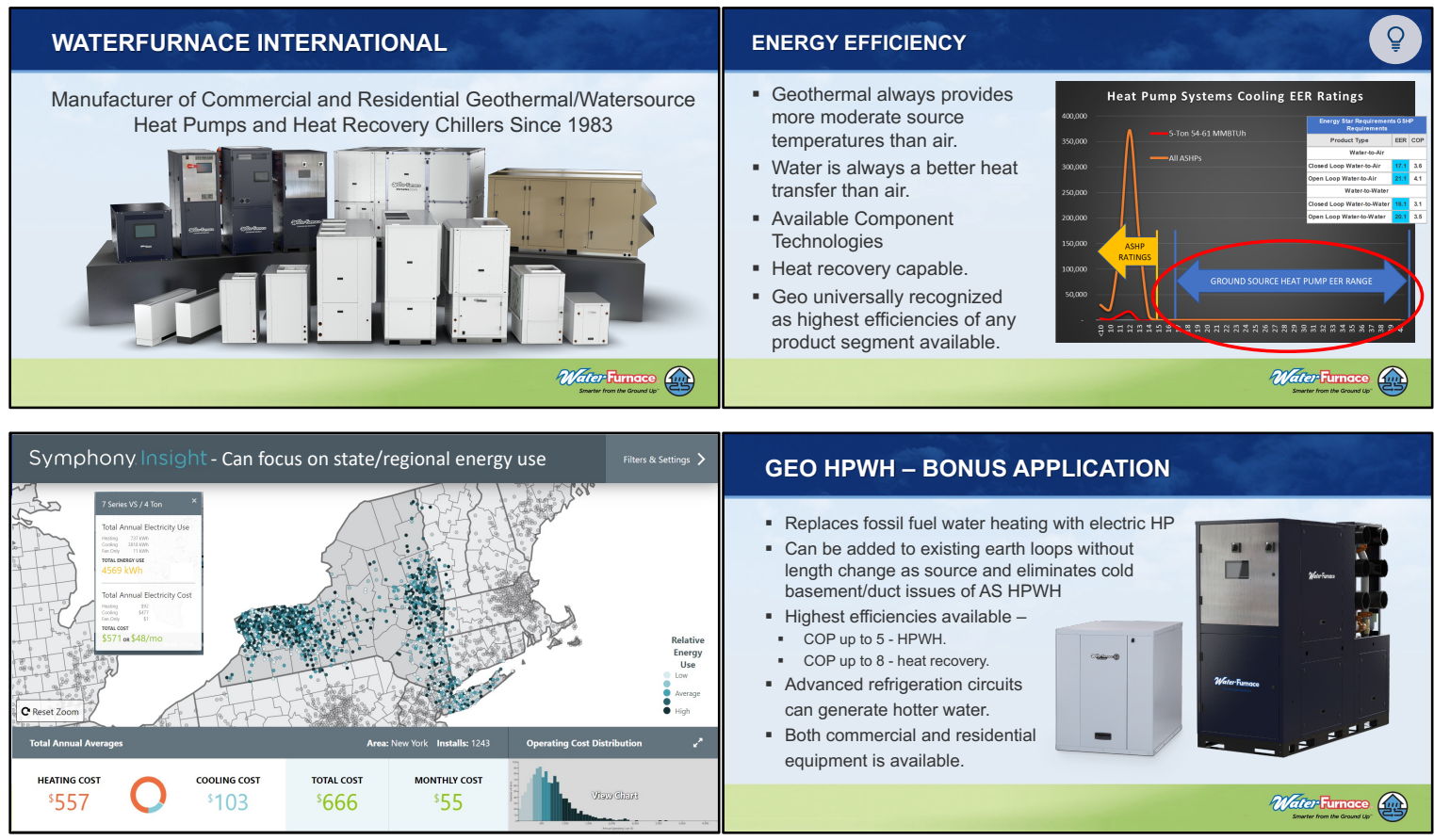

Figure 5. Slides from Robert Brown's (WaterFurnace) presentation. 


\subsection{APPROACHING RETROFITS TO DECARBONIZE AND PROVIDE GRID- INTERACTIVE RESILIENCE}
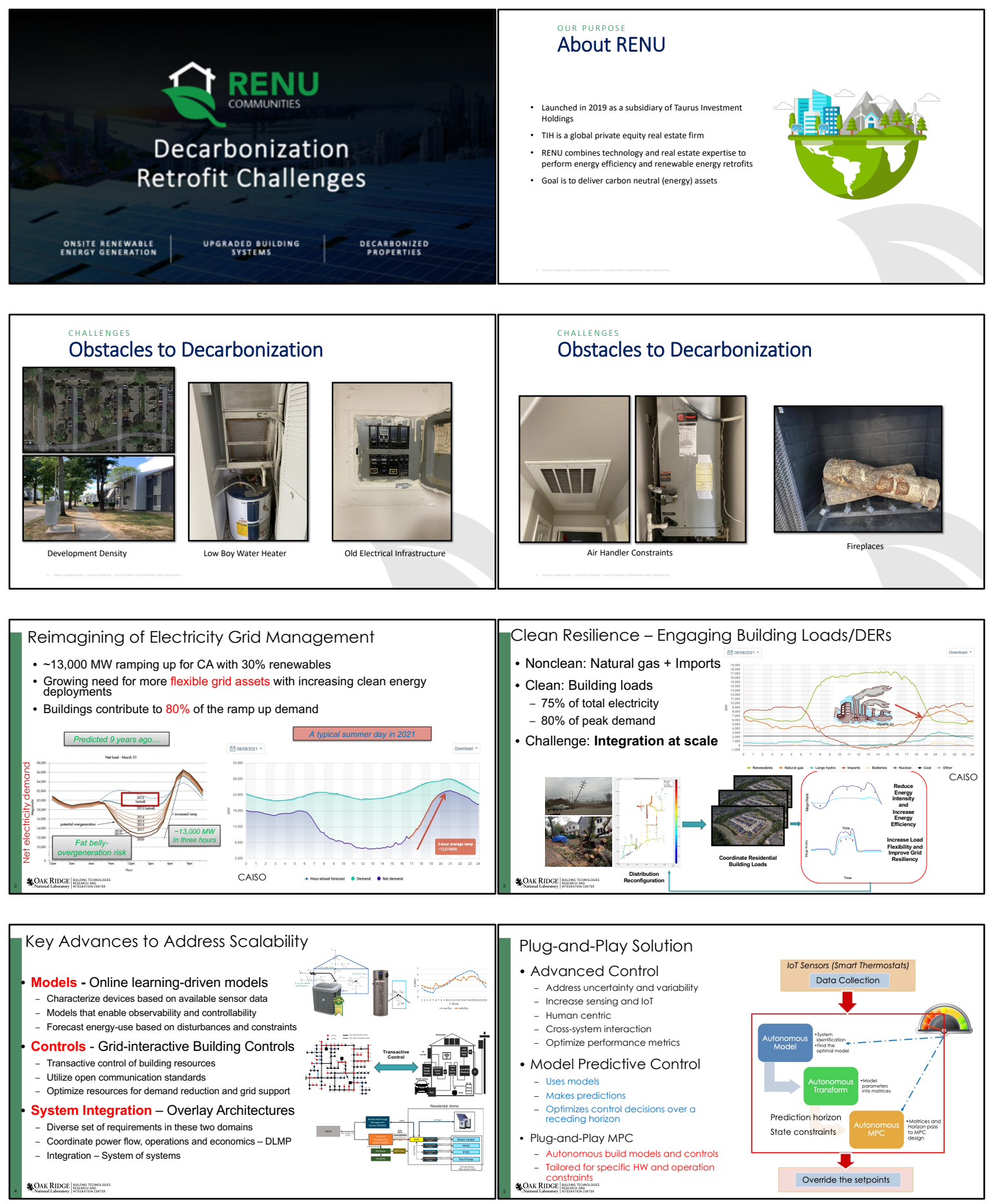

Figure 6. Slides from Chris Gray's (RENU Communities) presentation. 


\subsection{ENABLING CONNECTIVITY AND BENEFITS FROM DATA-TO-INSIGHTS}
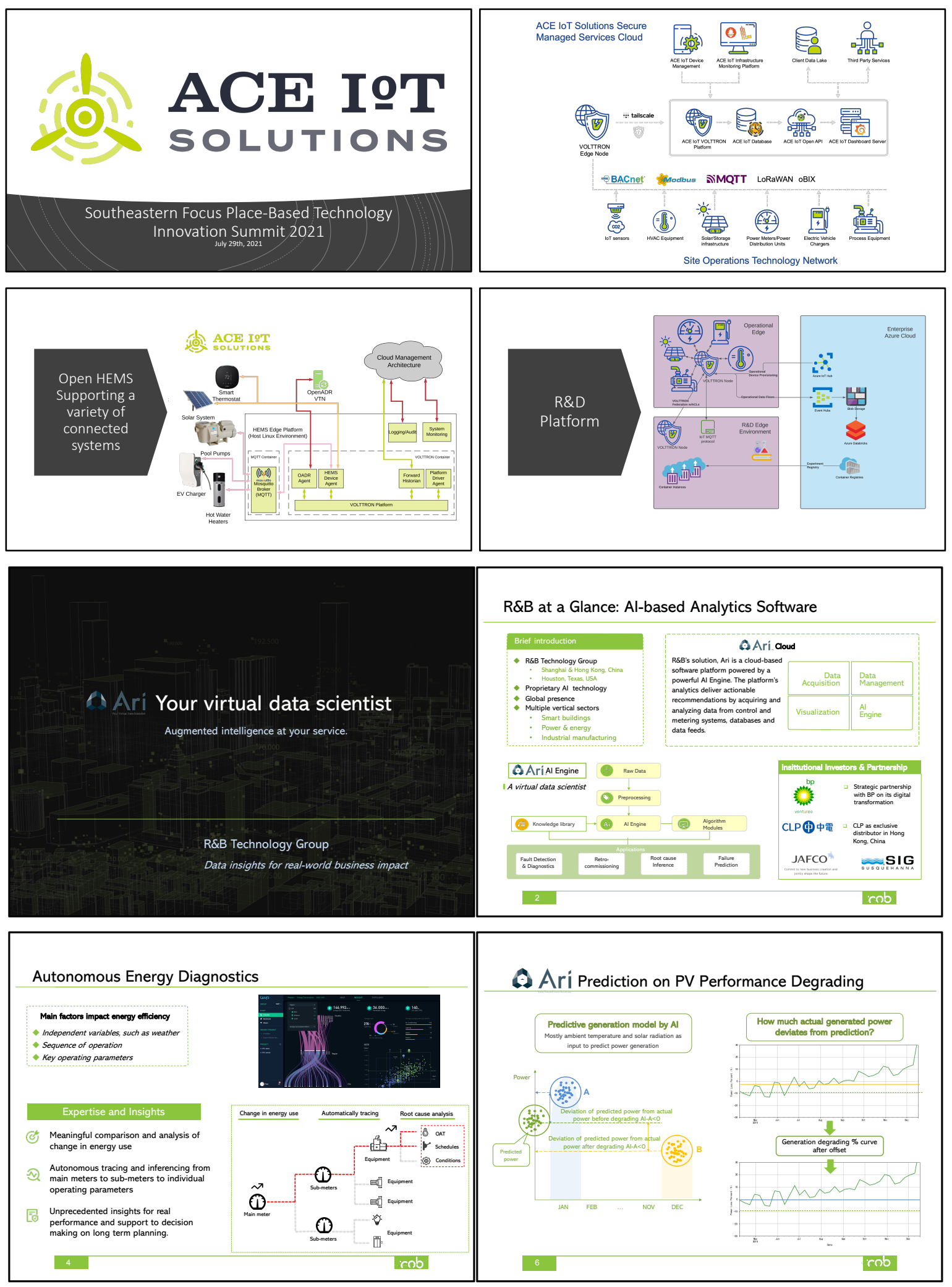

Figure 7. Slides from Andrew Rogers's (ACE IoT Solutions) presentation. 


\section{BARRIERS: WHAT ARE COMMON, SHARED NEEDS OR ROADBLOCKS FOR THAT FUTURE STATE?}

The group has identified several barriers, including educational awareness, technical limitations, policy environment, system first costs, and system operational costs. Because most connected community deployments have been in higher-income neighborhoods, we wanted to discover the barriers that are preventing deployment in low- to moderate-income communities, possible solutions to address this inequity, the partnerships that are necessary to overcome these barriers, and the role that national labs and DOE can play to overcome these barriers and help accelerate connected community adoption.

The group also identified institutional, technology-related barriers that exist within the connected technologies sector. These are the barriers that ORNL scientists encountered as they pioneered the concept of connected communities. All projects, developers, and communities will face these institutional, technology-related barriers. ORNL's involvement and strengths in these projects span the following areas:

- Scale and replicability. As in all prior connected community projects, ORNL seeks to focus on developing solutions that could scale transfer to other communities and utilities. These solutions must be extensible, adaptable, and based on open-source solutions. The foundations of these solutions are in their extensibility, adaptability, and investment in open-source solutions rather than simply choosing popular closed/black box solutions or declaring certain vendors as winners. To accomplish this goal, all solutions require interoperability and cybersecurity - two of ORNL's focus areas.

- Interoperability, common use cases, and data. ORNL seeks solutions that are standards-based and demonstrate interoperability to benefit a large portion of the population. Defining interface requirements enables nontraditional suppliers or new-to-the-marketplace entities and technologies to compose solutions and services that avoid the traditional heterogeneous, single-vendor solutions in building automation. Scalability can be promoted by leveraging similar building and equipment types that are prevalent or have similar control functionality (e.g., supermarkets and packaged HVAC units). Accordingly, ORNL believes in developing a collective response to define consumer and utility use cases and institutional concepts, such as data and control standards, shared architecture, similar interoperability specifications, open cybersecurity options, and clear privacy standards and provisions to protect PII.

- Modeling methods and evaluation of benefits. Evaluating consumer, utility, and manufacturing benefits is an important, outstanding area that ORNL seeks to research. Articulating these values is necessary to see change at scale and for all socioeconomic groups. Furthermore, transparency in deployment costs, technology costs, and adoption may help scale solutions and encourage small businesses into this space, primarily the integration space, to build a workforce and industry that support connected communities beyond the pilot stage. Simply put, ORNL wants others to benefit from the public investment, and it is from this position that ORNL provides stewardship.

- Communication, transport, cybersecurity, and privacy. Open, standards-based solutions with defined levels of interoperability and architectural considerations for demonstrating interoperability at device and application levels are required. For example, from prior research developed by ORNL in collaboration with Southern Company, cybersecurity and data privacy are managed using one or more service-oriented middleware layers. This solution can be leveraged for future deployments to effectively manage performance and security. Another key capability at ORNL is end-to-end data management to include data from the deployment along with metadata to describe the context of the use cases. 
It was clear from the discussion that more time should be spent evaluating impediments to projects, but this discussion should include a broader group than only technologists.

\section{PERSPECTIVES FROM THE TVA}

Through TVA's work with local power company partners and stakeholders as part of the integrated resource planning process, TVA identified market changes and gaps. From this data, TVA created six transformative initiatives to address these gaps:

(1) Regional grid transformation: developing an interconnected, intelligent grid able to reliably deliver power as it evolves

(2) Electric transportation: enabling adoption of electric vehicles in the Tennessee Valley that will provide environmental and economic benefits to everyone, regardless of whether they own or drive an electric vehicle

(3) Storage integration: implementing a long-term strategy to integrate energy storage that will provide system flexibility and improve our ability to maximize renewable energy sources

(4) Advanced nuclear solutions: developing a reliable, affordable, flexible, and clean generation nuclear option

(5) Decarbonization options: developing feasible technology pathways to achieve the next phases of carbon reductions and offsets

(6) Connected communities: expanding smart technologies with communities to manage energy and services

Connected communities are exciting because they provide broad opportunities and bring many innovative technologies together with communities and businesses.
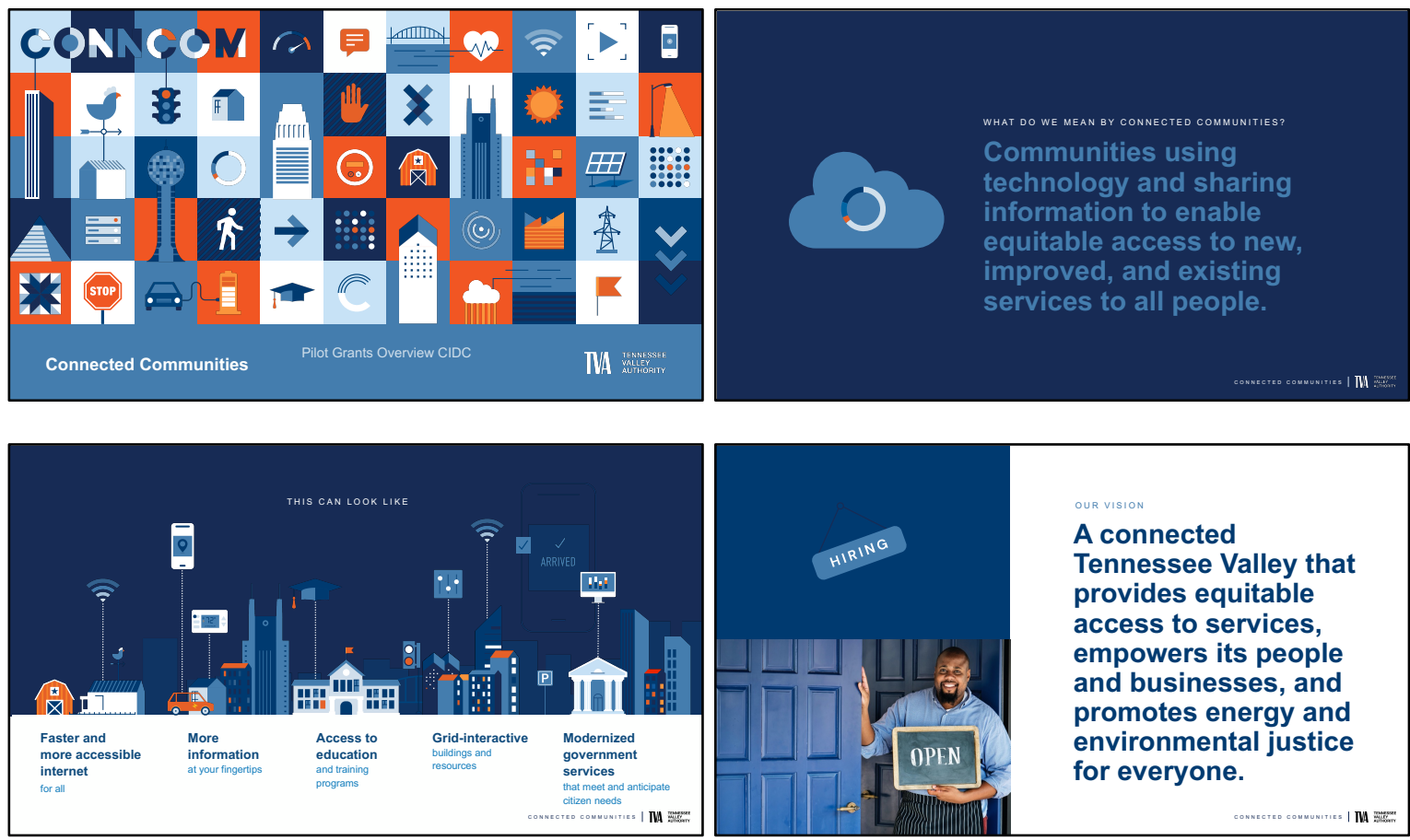

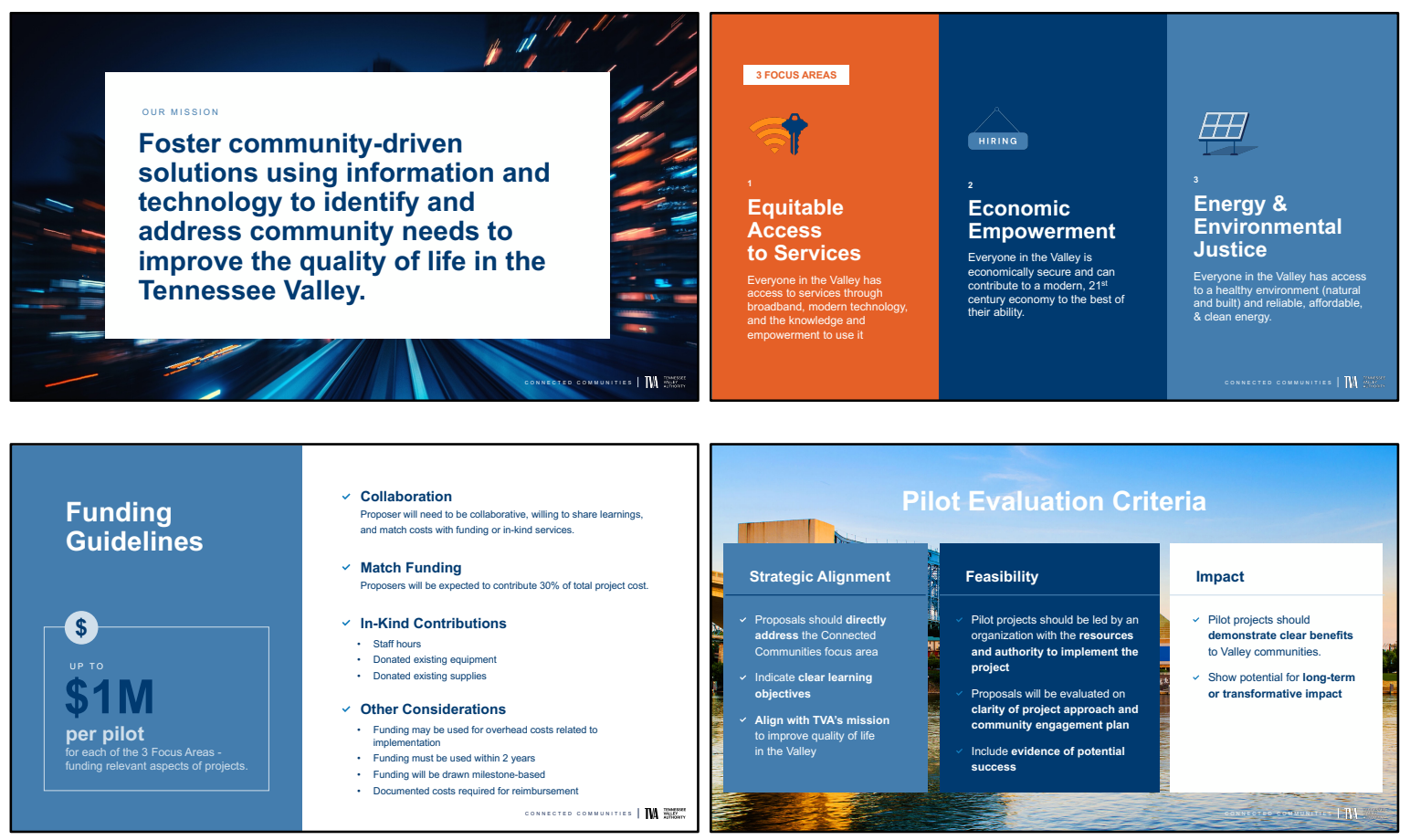

Figure 8. Slides from Bonnie Latta's (TVA) presentation.

Connected communities empower neighborhoods and families by providing

- faster and more accessible internet access for all;

- more immediate information - from home energy use to the nearest parking spot;

- $\quad$ education and training programs to prepare people for the technology-focused future;

- $\quad$ grid-interactive buildings and resources; and

- government digitization and modernization to increase efficiency, accessibility, and transparency.

Taking ACTION: Since the summit, ORNL is working to involve any selected TVA regional project that is of value to DOE's goals and programs. As such, ORNL is helping community members partner with TVA's Connected Communities Call for Pilots. 


\section{APPENDIX A. DEFINITIONS}




\section{APPENDIX A. DEFINITIONS}

Having clear definitions ensures that we understand each other. If you have a question about a term or a concept, please speak up-you are likely not alone.

- Smart homes or smart, connected homes are homes that have a connection to the utility such that the utility can understand the customer's usage and transact with them for reductions, demand response, increased consumption (e.g., storage), or ancillary utility services.

- Homes are smart in the sense that their controllers can talk among themselves and to others outside the home (e.g., other homes, the utility, or service providers).

- A connected community is a group of grid-interactive efficient buildings with diverse, flexible enduse equipment and other distributed energy resources that collectively works to maximize building, community, and grid efficiency without compromising occupant needs and comfort.

- Communities are smart in the sense that the homes can work together and have the community connection to the utility. The community can control the gross shape of its load, while the houses determine how to achieve their internal goals without service disruptions. Therefore, the homes must transact, sharing information or actions with one another, to achieve the goal of the community.

- High-performance homes are homes that have top-tier equipment or above code/above ENERGY STAR demand-side management and energy efficiency measures. They may contain one or two connected devices (e.g., a thermostat) to participate in demand response, but no holistic approach or deeper relationship with the utility exists, other than a special rate (for selecting the product) or other incentive (e.g., monetary refund if the user participates in a demand response event).

- High-performance neighborhoods are collections of these top-tier houses that as a group do not have a community connection to the utility, other than being customers. They are not leveraging community control concepts to deliver anything in gross to the utility. They are independent.

- Place-based approaches align local development or community frameworks with local plans to meet a larger national or regional goal, create mechanisms that enable planning across traditional boundaries, address regional disparities or access to social infrastructures, or provide solutions to address internal barriers across groups and communities. Place-based approaches harness the power of data and idea sharing to promote access to information for all parties during planning or implementation to facilitate meaningful, shared discussions of the future.

- Place-based approaches are useful for creating a shared vision and ensuring better coordinated delivery, learning, and honing of potential solutions that give due attention and respect to all relevant perspectives from an equal share of the community. 
APPENDIX B. SUMMIT WORKBOOK 
'Adapted from ElA estimate from 2011

${ }^{2}$ Adapted from EIA, Annual Energy Outlook 2013, Tables 2 and 9

${ }^{3}$ EIA data on peak demand

${ }^{4}$ Released on June 16, 2021 by the National Association of Realtors and authored by the Rosen Consulting Group, "Housing Is Critical Infrastructure: Social and Economic Benefits of Building More Housing" highlights the vast underinvestment in building and the gap created in the U.S. Following decades of "underbuilding", the U.S. faces an acute shortage of available housing, an ever-worsening affordability crisis, and an existing housing stock that is aging and increasingly in need of repair. See the National Association for Realtors for more information. 


\section{Welcome}

Southeastern Focus Place-Based Technology Innovation Summit

Each year, more than $70 \%$ of the nation's total electricity, 3,856 billion kilowatt-hours, is consumed by 117 million households and 5.5 million commercial buildings. ${ }^{1}$ This makes the integration of these buildings into a smart grid critical to decarbonizing while reducing peak loads and keeping associated infrastructure costs down. Moreover, most of the load growth projected by the US Department of Energy (DOE) and the US Energy Information Administration through 2040 will be driven by buildings, which will drive projected capacity expansions. ${ }^{2}$ Many smart grid applications, especially demand response, are designed to minimize peak demand, ${ }^{3}$ but distributed generation and storage (both electric and thermal) may also make important contributions as costs come down. Concurrently, housing is in steep demand after years of underinvestment in new housing starts. ${ }^{4}$

The opportunity before the nation is great: create a clean, smart grid that is interconnected with smart buildings to manage load and generation in real time. To do this, we must vastly expand the number of homes, customers, and types of end-uses engaged in this effort while utilizing the smart grid's communication technologies to interact with customers and connected appliances, equipment, and devices. These future solutions will require science-based advancements and new technologies.

We are all at the forefront of change, and this summit will help define the future state we collectively hope to achieve. The future grid-along with the homes, communities, and families that it powers - must provide a seamless, cost-effective electricity system, from generation to end-use, with the flexibility to accommodate all clean energy sources and capacity requirements. The challenge of addressing variable resources is part of a larger grid modernization agenda that must address many other profound changes in the nation's infrastructure, such as how best to use natural gas, increased consideration of distributed generation, limited ability to expand transmission, and measures to add flexibility to the system, including energy storage.

These challenges, or more accurately opportunities, drive DOE's Oak Ridge National Laboratory (ORNL). We are the largest DOE science and energy laboratory, able to access vast scientific resources to open up opportunities in innovation. The future grid will require this type of innovation to allow for significant scale up of clean energy, universal access to consumer participation and choice, holistically designed solutions, and two-way flows of energy and information, along with reliability, security, and resiliency. This vision can only be successful if it is supported by cutting-edge science. That is the driver of this summit and ORNL's continued focus on thoughtful, meaningful place-based research.

At this meeting, we plan to connect, to understand, and to explore the challenges that all communities face on the path to the future. We hope that our science can be shaped by your needs and your vision. Furthermore, we hope this is only the first step in an ongoing journey in which we work together to achieve this admirable goal while recognizing that this future must be inclusive, diverse, and meaningful to all communities and all families. It is our responsibility as a national laboratory and as industry leaders to make this possible.

Welcome to ORNL, Dr. Xin Sun 


\section{Southeastern Focus Place-Based Technology Innovation Summit}

\section{Definitions}

To get started, we must have clear definitions to ensure we do not speak past one another unknowingly. If you have any questions about a term or a concept, please speak up-you are likely not alone, and we need to ensure all participants share common definitions and terms.

- Smart Homes or Smart, Connected Homes are homes that have a connection to the utility such that the utility can understand the customer's usage and transact with them for reductions, demand response, increased consumption (e.g., storage), or ancillary utility services.

— These systems are "smart" in the sense that their controllers can talk amongst themselves and share information with others (e.g., other homes or the utility or service providers).

- A Connected Community features grid-interactive, efficient buildings with diverse, flexible end-use equipment and other distributed energy resources that collectively work to maximize building, community, and grid efficiency.

- Connected communities are "smart" communities in the sense that the collection of homes can work together and have a community connection to the utility. In that sense, the community can control the gross shape of its load while the houses determine how to achieve their own internal goals without service disruptions. Hence, the homes must "transact," by sharing information or actions with one another, to achieve the goal of the community.

- High-Performance Homes are homes that have top-tier equipment or are above code/ENERGY STAR demand-side management and energy efficiency measures. They may contain one or two connected devices - like a thermostat - to participate in demand response, but there is not a holistic approach or a deeper relationship with the utility other than a special rate (for selecting the product) or per "hit" incentive (e.g., monetary refund if the user participates in a demand response event).

- High-Performance Neighborhoods are ccollections of these top-tier houses that, as a group, do not have a community connection to the utility other than being customers. They are not using community control concepts to deliver anything in gross to the utility. They are all independent.

- Place-Based Approaches align local development or community frameworks with local plans to meet a larger national or regional goal, create mechanisms that enable planning across traditional boundaries, address regional disparities or access to social infrastructures, or provide solutions to address internal barriers across groups and communities. Place-based approaches harness the power of data and idea-sharing to promote access to information for all parties in planning or implementation to ensure meaningful shared discussions of the future.

- Place-based approaches are useful in creating a shared vision and ensuring better coordinated delivery, learning, and honing of potential solutions that give due attention and respect to all relevant perspectives from an equal share of the community. 


\section{Plenary}

\section{DAY 1}

Welcome to ORNL and the Harding Valley Campus

Dr. Moe Khaleel, Deputy Laboratory Director

\section{Setting Expectations}

Meeting Goals to See the Best in Science, Placed Based Action in Our Communities

Dr. Xin Sun, Associate Laboratory Director

\section{Perspectives from National Leaders}

Remarks on Place-Based Innovation

Ms. Johanna Zetterberg, DOE

Dr. Alyse Taylor-Anyikire, DOE

Ms. Erika Gupta, DOE

\section{Perspectives from Regional Leaders}

Ms. Molly Cripps, Tennessee Department of Environment and Conservation's

Ms. Erin Gill, Chief Policy Officer and Deputy to the Mayor, City of Knoxville

\section{Around the Room Introductions}

Mr. Joe Hagerman, Facilitator

- Clayton Homes as it seeks to be a world-class producer of the best, advanced homes for all

- Knoxville Community Development Corporation as it seeks to be a model for the community and nation in decarbonization

- Tennessee Valley Authority (TVA) local power companies representing the municipal utilities and the cooperative utilities as they seek to build and support communities of the future

- Invited guest: Catey McClary, Great Smoky Mountains Institute at Tremont

- Introduction to local companies that offer energy-related technologies

- Introduction to ORNL's world-class building innovation staff

- This meeting focuses on taking science-based action to help realize decarbonized, place-based, clean energy interventions that are equally shaped by, inspired from, and committed to, the communities that are served.

- We collectively seek to make clean energy technologies applicable, relevant, and impactful for all communities through the various scales of place-from Knoxville to the Tennessee valley region to the whole Southeast.

- This meeting will match researchers and businesses with community groups that are actively creating change in the built environment.

- The outcome will be clear decisions, action plans to realize change, and connections to those that can augment, leverage, and otherwise make a real impact in the communities, neighborhoods, and places that families call home, that citizens call community, and that define us as a region. 


\section{DAY 1}

\section{Session 1 \\ Project Goal Setting to Lead Innovation}

This session will focus on defining your goals for place-based success and propose pathways to reach them. Our hope is that this discussion will help define the end state of success (i.e., your vision of the future) for the group and also shape and improve that vision and your mission to get there, given the needs to support the best science, the inclusion of all people and thoughts, and community drivers of change.

\begin{tabular}{|l|l|}
\hline $\begin{array}{l}\text { Inspirational } \\
\text { Speaker }\end{array}$ & Bonnie Latta, TVA - The Opportunity of Connected Communities \\
\hline $\begin{array}{l}\text { Assignment } \\
\text { Speaker }\end{array}$ & $\begin{array}{l}\text { Joe Hagerman, ORNL - Project Vision Mission and Goal Development. Setting goals is important to understanding our } \\
\text { targets and the value of the change to customers, community members, and families of the places we are building. }\end{array}$ \\
\hline Working Time & $\begin{array}{l}\text { In Groups - Discuss where you are today in your thinking about connected communities, buildings, and programs that will } \\
\text { change place and energy use. }\end{array}$ \\
\hline Conversation & All - General discussion, sharing, and learning. \\
\hline
\end{tabular}

\section{Strategic Alignment of Organization's Vision, Mission, and Goals}

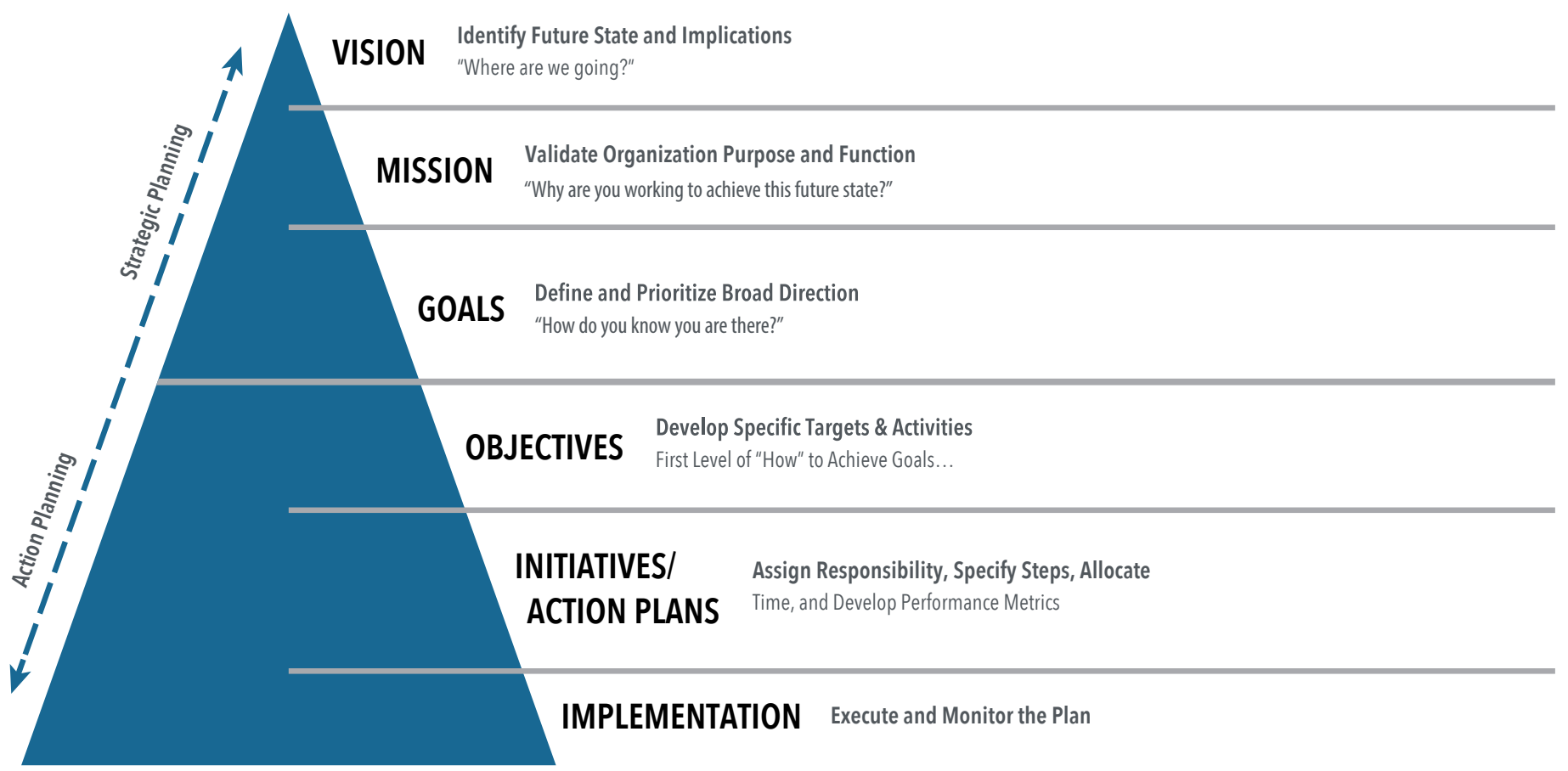




\section{Mapping Vision, Mission, and Goals}

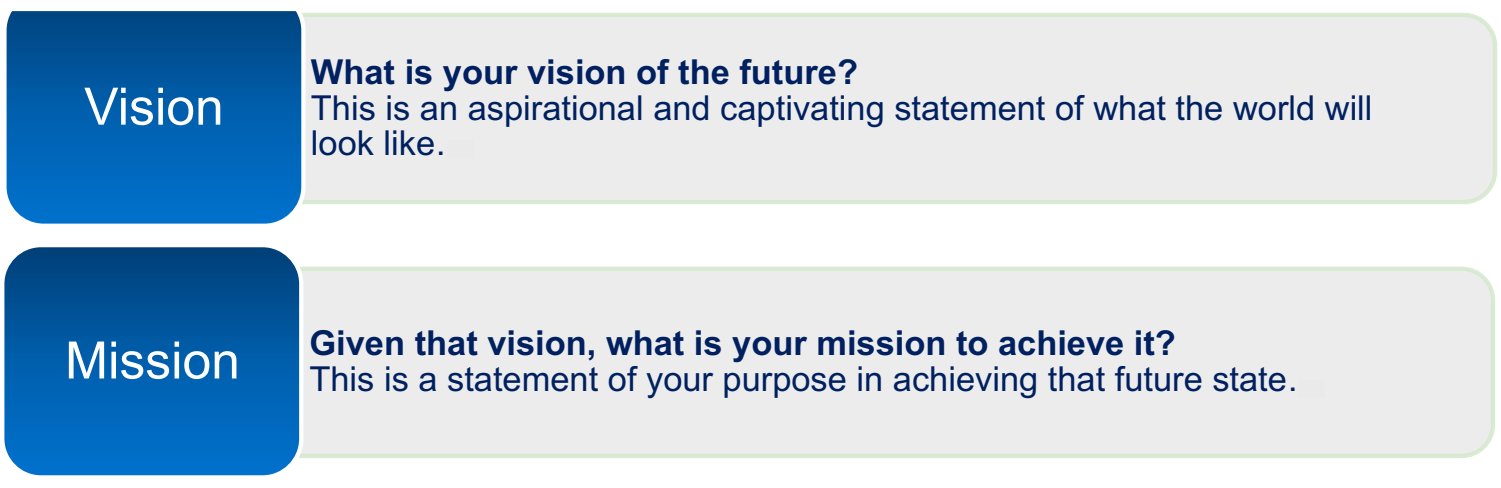

\section{GOALS}

GOALS are achievable outcomes for which you are responsible:

\section{Goal 1}

The first goal as an understandable sentence.

\begin{tabular}{|c|c|c|c|}
\hline Goal & Objective & $\begin{array}{c}\text { Example Activities } \\
\text { (in no particular order) }\end{array}$ & P.O.C \\
\hline
\end{tabular}




\section{DAY 2}

Connected consumers demand greater access to building options within sustainable communities and smart cities while providing residents with greater consumer benefits, wellness, and resilience. What if we reimagined quality housing, neighborhoods, and communities as the prescription for a healthy life and the future of sustainable communities across the nation from better connections to local utilities? Utility-connected smart neighborhoods and communities can be cost-effective investments for cities, utilities, and consumers by leveraging the stature of the utility in the community.

One of the most important metrics to utility leadership is customer satisfaction. Utilities have historically been the trusted energy provider in a city - where it is a local municipal utility, a rural electric utility, or an investor-owned utility. Whether they are conscious of it or not, a utility has an imprint on a city - from the wire and infrastructure they support to the employees that service fellow neighbors and families. A utility is often a respected part of the community, a supporter of events, and the power lighting the little-league night game. Consumers want a better relationship with their energy provides, and connected communities are an effective bridge between the two.

\section{Session 2}

\section{Technology Innovators Leading the Future}

This session is a roundtable on innovative, affordable, energy-efficient, low-embodied carbon technologies for communities in the Southeast. These experts include ORNL's technical leaders (in heat pumps, multifunctional equipment, active envelope systems, and controls for grid-interactive buildings) and our invited industry partners. The format of this session starts with ten to twelve 5-min "Technology Speed Dating" presentations (2 slides) explaining who you are, what the technology is, and why it is important.

\begin{tabular}{|c|c|}
\hline ORNL & Invited Industry Experts \\
\hline Advanced construction/envelopes & Heat pump water heaters \\
\hline Cold-climate heat pumps & Heat pumps \\
\hline Integrated equipment & Open-source home energy-related management \\
\hline Grid-interactive Efficient Buildings + Volttron & Data and machine learning/artificial intelligence \\
\hline Direct Air Capture & Sustainable materials \\
\hline
\end{tabular}

Assignment

Speaker

Working Time

Conversation
Joe Hagerman, ORNL - Technology Selection. Working with the technologies and subject matter experts, work through the details on how your model project can use or apply the technologies to help meet your goals. What changes or considerations to the projects or to your goals must be made? Which pieces of your goals are easy to achieve? Which are harder to achieve and why?

In Groups - Working in groups and with the technology experts as consultants, select the technology group that is of interest and discuss how it should be applied, its ability to help your goals, and positives/negatives of the technologies. Is there something that needs to be changed to make it fit?

All - General discussion, sharing, and learning. 


\section{Technology Categories (adapted from the Federal Energy Management Program)}

This attachment lists the technology categories (TCs) and related energy conservation measures that are suggested for evaluation. The identified energy conservation measure examples do not include all potential energy conservation measures. Work with the technology experts to help expand or increase the list of options for all partners.

\section{TC.3 Building Automation Systems/Energy Management Control}

Systems

- Building automation systems/energy management control systems

- Control and algorithm solutions

\section{TC.4 HVAC Improvements}

- Packaged air conditioning unit

- HVAC damper and controller

- Economizers

- Fans and pump with control

- Thermal energy storage

- Variable air volume solutions

\section{TC.5 Lighting Improvements}

- Interior and exterior lighting

- Intelligent lighting controls

- Occupancy sensors

- LED technologies

- Daylighting

- Spectrally enhanced lighting

- Fiber optic lighting technologies

\section{TC. 6 Building Envelope Modifications}

- Insulation

- Windows

- Reflective solar window tinting

TC.7 Water, Hot Water Distribution Systems

- Piping insulation installation

- Hot water heater

TC.8 Electric Motors and Drives

- High-efficiency motors

- Variable speed motors or drives

\section{TC.10 Distributed Generation}

- Cogeneration systems

- Micro-turbines

- Fuel cells

\section{TC.11 Renewable Energy Systems}

- Photovoltaic systems

- Solar hot water systems

- Solar ventilation preheating

- Wind energy system

- Passive solar heating

- Geothermal heat pump systems

TC.12 Energy/Utility Distribution Systems

- Transformers

- Power quality upgrades

- Power factor correction

- Gas distribution systems

\section{TC.13 Water and Sewer Conservation Systems}

- High-efficiency plumbing fixtures: toilets, urinals, faucets, and showerheads

- Water-efficient irrigation and landscaping

- Leak detection and repair

- Storm water management

- Water-efficient kitchen equipment

- Alternative water systems (e.g., rainwater harvesting, reclaimed wastewater, and condensate capture systems)

TC.14 Electrical Peak Shaving/Load Shifting

- Thermal energy storage

TC.16 Energy Related Process Improvements

- Recycling and other waste stream reduction

TC.18 Advanced Metering Systems

TC.19 Appliance/Plug-Load Reductions

- Plug timers

- ENERGY STAR products

TC.20 Other/Future ECMs - Other Measures 


\section{Session 3}

\section{Leading into Tomorrow by Overcoming Barriers}

\section{Identifying Our Needs to Enable a Shared Future}

Barriers exist to scaling connected communities to all communities. To what degree do you believe those barriers are rooted in...

- Educational Awareness?

- Changing Policy Environment?

- Technical Limitations?

- System Costs - first costs and ongoing operational costs?

Connected Communities to date have been in higher income neighborhoods.

- What barriers are preventing adoption in the low to moderate income communities?

- More importantly, what can we do to address this inequity?

- What partnerships are necessary to overcome these barriers?

- What role can a national laboratory play to help accelerate adoption?

\section{Assignment Speaker}

Joe Hagerman, ORNL - Barriers to place base innovation and innovative community deployment can take various forms.

Conversation

Institutional and technology related barriers also exist within the connected technologies sector. These are the barriers that ORNL scientists have encountered as we pioneered the concept of connected communities. These institutional technology related barriers will be faced by all projects, all developers, and all communities.

Issue 1: We must agree on terms to define the sector.

- Does"a connected home" = "a smart home" = "home energy management?"

- How do we agree upon a shared, common definitions of connected equipment, smart equipment, and energy management features?

A "Connected Community" refers to the concepts of energy management and device control through the access of connectivity and information and not physical products. The ideas and principles of Connected Communities are larger than any singular physical device, platform, or multitude of networked physical devices, or related product offerings. 
Issue 2: Cyber-physical security (e.g., cyber-security) must be addressed at all levels rather than simply applying principles ad-hoc.

- Can we define the appropriate level of cyber security for a Connected Community?

- How can we minimize the costs associated with obtaining that appropriate level of protection?

All Connected Community functions rely heavily on communication (referred to as Information and Communications Technology). Optimizations rely on data exchanged and the commingling of data between different systems with the ability of products to leverage the sensing and data acquisition capabilities within the products. One important characteristic of connected buildings - which is particular to the breadth of buildings across the nation - is that the equipment and devices span the range of complexity and cost just as the building uses and tenants range in degrees of sophistication, criticality, and income. Yet, the cyberattacks do not discriminate - they attack no matter the use, location, or facility's importance.

Issue 3: Connected equipment intersects and could expose the privacy and protection of personally identifiable information (PII).

- How do we discuss, understand, and manage PIl so that consumers are protected but critical data and information about the systems can still be shared externally?

Building occupants are becoming increasingly connected to the outside world through wired and wireless networks, smartphones, and related communication products. These devices and their users interact inexpensively and persistently over time with relative anonymity, which may present multiple challenges and opportunities for the sector. These features also put consumer information, schedules, and other operational data, which may be user sensitive, at risk of exploitation or impermissible sharing with some or all outside parties.

Issue 4: We always seek seamless interoperability across technologies.

- How can solution providers' technologies easily work together so we can live up to consumer's expectations of solutions "just working" without frustration?

The desired state of technology interoperability is where end-use resources (e.g., generation, storage, loads) can seamlessly communicate and transact (and benefit from) a range of energy services being exchanged across the meter with the utility and with other end-use loads or generation.

Issue 5: Establishing and communicating the consumer value of smart connected homes and equipment is essential.

- What is the value to homeowners beyond being able to control devices from anywhere?

- What is the business case for Manufacturers? How does that information drive understanding faults services and managing service calls?

- What is the business case for utilities? Is it both the ability to capture grid services for energy efficiency and increased renewable generation?

Clear value to the market will ultimately determine scale and impact. 


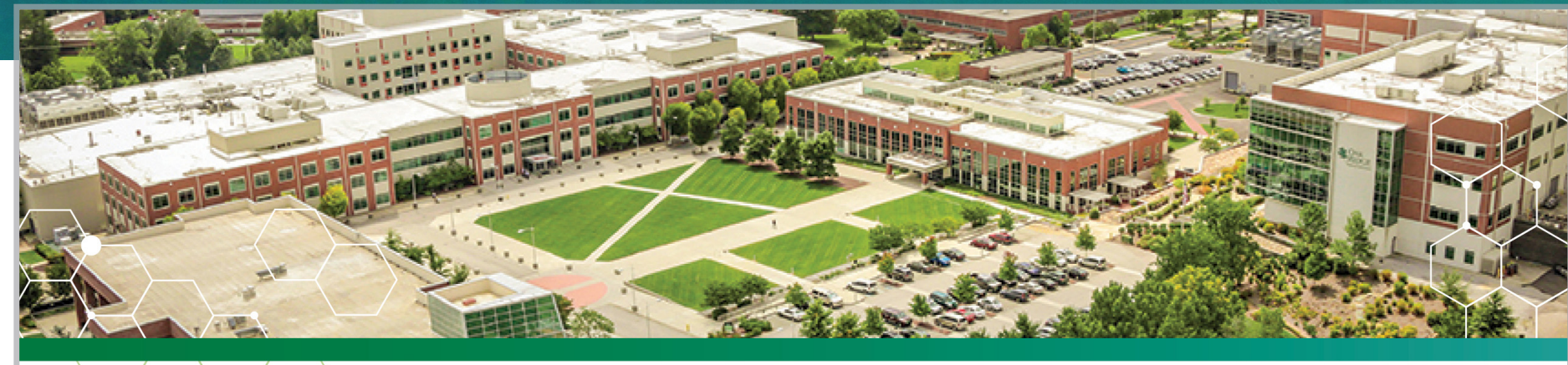

\section{Impact of Connected Communities: FY21 Results}

\section{Introduction}

Buildings account for $35 \%$ of $\mathrm{CO}_{2}$ emissions and almost $40 \%$ of the United States' energy use. ${ }^{1}$ High-performance homes and neighborhoods play an important role in supporting the energy industry's move to decarbonize by 2035 . Significant reductions in $\mathrm{CO}_{2}$ emissions within the residential sector can be realized through electrification of loads paired with the flexibility created by leveraging smart Internet of Things (IOT) capabilities to shift energy use based on grid signals, thus improving generation/distribution efficiency and maximizing the use of renewable generation capacity. All of this can be achieved while allowing smart home appliances and equipment to meet homeowner needs while optimizing operation in conjunction with the grid using novel control techniques. The Grid-Interactive Efficient Buildings Roadmap ${ }^{2}$ by the US Department of Energy's Building Technologies Office (BTO) notes that implementing grid-interactive efficient building (GEB) technology has the potential to reduce $\mathrm{CO}_{2}$ emissions by 80 million tons/year-roughly equivalent to 17 million cars.

To achieve this vision, the US Department of Energy's Oak Ridge National Laboratory (ORNL) -in collaboration with Southern Company Research \& Development, Alabama Power, Georgia Power, and BTO-is developing and demonstrating novel connected communities at two locations. Southern Company in turn engaged with industry partners, including design firms, residential developers, and residential HVAC and appliance manufacturers because their participation would be critical to the success of the initial research project, as well as the future scaling to the Southern Company service territory and beyond.

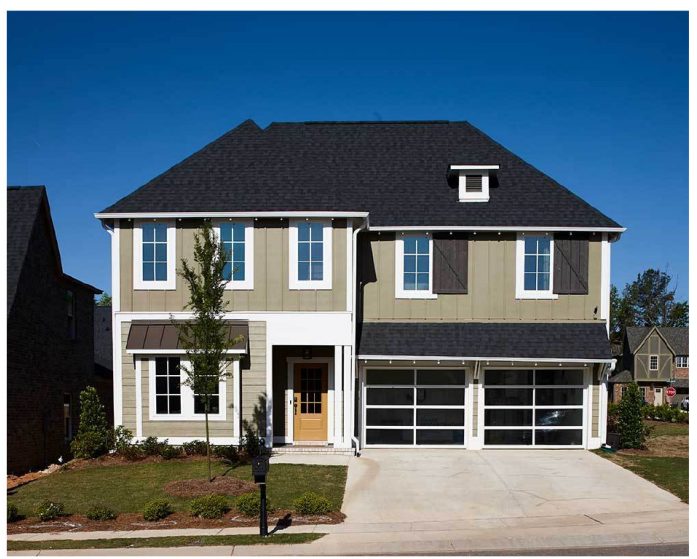

Alabama Power Smart Neighborhood $®$ Idea Home. Image courtesy: Alabama Power.

Through its Smart Neighborhood $®$ program, Alabama Power led the design and development of a community of 62 single-family homes in Hoover, Alabama to include utility-owned, community-scale distributed energy resources (solar, battery storage and backup natural gas generator). The Reynolds Landing at Ross Bridge Smart Neighborhood $\AA$ development is the Southeast's first neighborhood to locally generate, store, and distribute power in conjunction with optimizing and controlling electrical loads within the neighborhood homes. Each home featured enhanced energy efficient components and systems including: $2 \times 6$ walls with blown-in insulation, triple pane low-e windows, attic radiant barrier, hybrid heat pump water heater, variable capacity heat pump, energy data monitoring center, induction cooking, smart outlets and lighting.

\footnotetext{
1 "About the Building Technologies Office," US Department of Energy Office of Energy Efficiency \& Renewable Energy. [Online] Available at https://www.energy.gov/eere/buildings/about-building-technologies-office.

${ }^{2}$ A. Satchwell et al., A National Roadmap for Grid-Interactive Efficient Buildings, Lawrence Berkeley National Laboratory, 2021.

[Online] Available at https://gebroadmap.lbl.gov/.
} 
Southern Company and Georgia Power developed the first Smart Neighborhood $(\mathbb{R}$ in Atlanta: Altus at the Quarter. The Altus neighborhood consists of 46 townhomes. In addition to energy efficiency upgrades in the form of high-efficiency heat pumps, smart thermostats, and hybrid heat pump water heaters, each townhome is also equipped with a rooftop solar power system, an inverter, two home energy storage batteries, and an electrical vehicle charger. Each home also includes a transfer switch and critical load panel to allow important loads in the home (refrigeration, select lighting and receptacles) to be powered from the home's batteries in the event of a grid outage.

\section{Learnings: Energy, Grid Services, and Data Management}

\section{Energy}

Based on analysis of annual energy data collected by ORNL, Southern Company, Alabama Power, and Georgia Power, both neighborhoods were substantially more energy-efficient than similar neighborhoods of all-electric homes that had been built to code minimums. Baseline performance of both neighborhoods was compared with similarly sized homes that were constructed to code minimum standards.

Data collected in 2019 showed that Reynolds Landing homes used 44\% less electricity than the baseline neighborhood. In 2020 optimization control of the homes was suspended temporarily during the period of the COVID-19 related "Safer at Home" order in Alabama. Data collected during this time provided insight into the usage patterns for home equipment and appliances and showed the continued benefits of the higher efficiency home design and construction. Comparing similar weather days in 2019 and 2020 showed that both the Reynolds Landing and the baseline neighborhood used more energy in 2020. More detailed evaluation of the circuit level energy use in the Reynolds Landing homes showed that during the "Safer at Home" order, certain loads (range, clothes washer, clothes dryer and water heater) used more energy as compared to the same time in 2019. The analysis also showed that daytime usage peaks occurred later in the morning and earlier in the evening. Even with the increased energy use by household appliances and equipment, the Reynolds Landing daily energy use in 2020 was still $21 \%$ lower than the baseline neighborhood.

Utility meter data and solar generation data from Altus homes shows that on average the Altus homes purchased $42 \%$ less electricity from Georgia Power than the homes in a similar baseline neighborhood. Excluding solar generation, the Altus homes used $20 \%$ less energy than the baseline neighborhood. This compares well with the original energy modeling for the neighborhood that projected $23 \%$ energy savings and 39\% less energy purchased with solar generation included.

\section{Grid Services}

In terms of grid services, the ORNL Oak Leaf optimization and dispatch system shaped and shifted loads by changing HVAC, water heater, and inverter set points ahead of real-time price increases forecast by the utility.

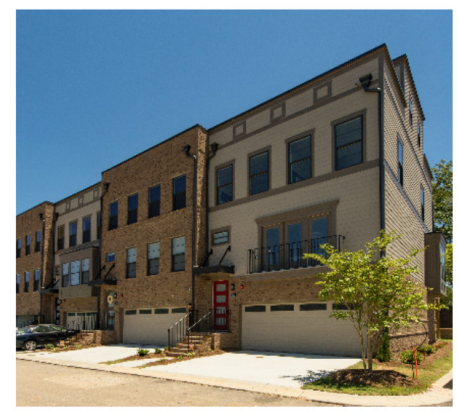

Altus neighborhood. Image courtesy: Georgia Power.

RESULTS
Reynolds Landing 2019
$44 \%$ less energy consumed than
baseline neighborhood
7,167 kWh saved per home on an
equivalent square foot basis
\$931 saved per home on an
equivalent square foot basis
5.6 tons of $\mathrm{CO}_{2}$ generation avoided
per home
Altus 2020
$42 \%$ less energy purchased annually
compared with baseline
neighborhood
$20 \%$ energy savings (excluding PV
generation) compared to baseline
neighborhood
Homes averaged 873 kWh sold back
to Georgia Power
In winter, $30 \%$ lower max hourly kW
demand than baseline
In summer, $62 \%$ lower max hourly
kW demand than baseline
9.3 tons of $\mathrm{CO}_{2}$ generation avoided
per home

At the Reynolds Landing neighborhood, HVAC power demand reductions of $15 \%$ were observed in summer operation, and water heater demand was reduced $43 \%$ in winter operation. 
The ORNL Oak Leaf optimization/dispatch showed 12\% demand (kW) reduction at the Altus neighborhood by precooling the homes in advance of an afternoon price peak. Testing is ongoing at the neighborhood, and similar or better results are anticipated for peak winter heating conditions.

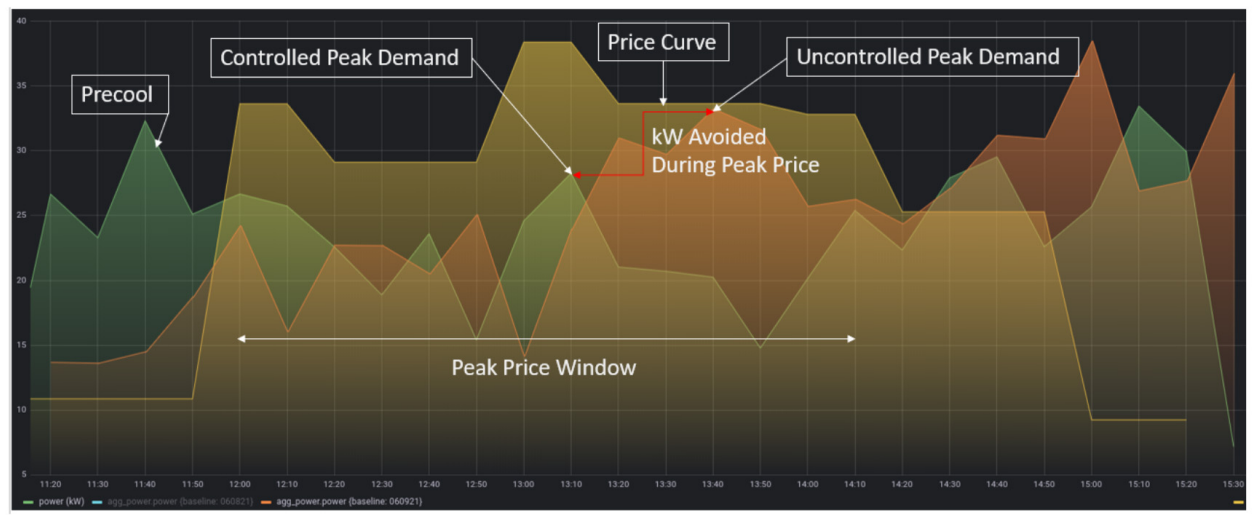

Altus Oak Leaf load shift showing the difference in peak usage during a peak price window (June 2021).

\section{Data Management}

For both neighborhoods, data infrastructure and communications methods were established by Southern Company and ORNL. Data was used to assess the state of devices, inform calculations for optimization, and assess the performance of optimization dispatch versus baseline operation. A layered approach was used to include the data acquisition/storage layer, the analytics layer, and the user interface/visualization layer. The project required development of infrastructure to extract, transform, and load data from

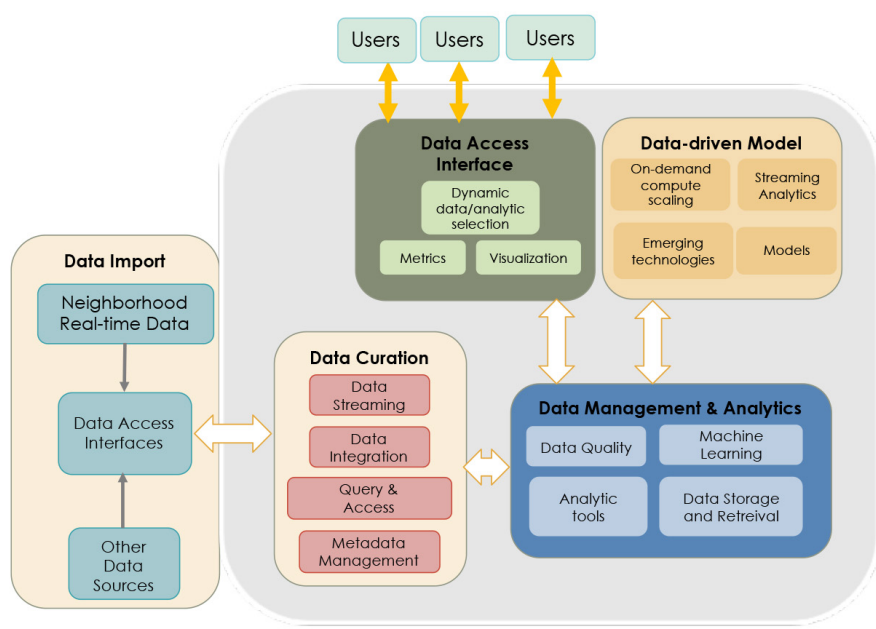

ORNL Data Management Framework. varying sources into specific databases. A framework for data warehousing was created using virtual machines and containers in the cloud. An ecosystem of tools was created to analyze and visualize data. Interactive dashboards were created to monitor system health and rapidly analyze trends using visual clues.

The learnings from the Reynolds Landing project were used to streamline the Altus data management and analysis. Data requirements were established to minimize data translations after acquisition. Automated routines and common databases were used to reduce infrastructure requirements. Flexible architecture was employed with cloud computing to accelerate analytics with elastic computing.

Data has related requirements in terms of confidentiality, integrity, and availability. To harvest data from different platforms and devices, a middleware is needed to abstract customer protected information and assist with scaling, without adding latency. In this research project, that functionality was provided by Southern Company's Residential Energy Service (RES) data system. Cloud computing enables data availability, and fault monitoring enables maintaining availability. 


\section{Homeowner Feedback}

At the Reynolds Landing neighborhood, Southern Company and Alabama Power conducted monthly homeowner surveys to gauge their opinions on smart home technologies and controls. Location and architectural design were the biggest drivers for buyers to purchase homes in Reynolds Landing, and smart home technology was the next most important factor in the purchasing process. Reynolds Landing homeowners reported using voicecontrolled home assistants, smart home security systems, and smart lighting controls/receptacles most often.

\section{The Homeowner's Viewpoint}

"I can make adjustments to ensure my home is well cared for. I can see what my home's electricity usage is with the click of a button, but I can also make any necessary changes due to humidity, temperature, or day-to-day preferences."

- Altus homeowner helpful. In addition, about half of Reynolds Landing homeowners suggested that an end-of-month recap of homeowner set point versus optimized set point would be helpful in understanding the set point changes made on their behalf for energy savings. Altus neighborhood homeowners were asked to identify which of seven smart home technologies was their favorite. $41 \%$ identified the rooftop solar system. Battery storage was the favorite for $18 \%$ of homeowners. Tied for third place with $12 \%$ each were energyefficient smart appliances, voice-controlled home automation systems, and home security systems.

\section{Most (65\%) Reynolds \\ Landing homeowners \\ reported that they only \\ occasionally noticed \\ temperature changes by the \\ GEB optimization.}

In Reynolds Landing, 71\% of

homeowners reported that they

noticed temperature changes as part of the grid-interactive operation of their home HVAC. Of that group, most (65\%) reported that they noticed these changes occasionally each week. This finding indicates how closely the home optimization system followed the preferred temperature ranges for the home and still provided energy savings through gridoptimized operation.

Homeowners who noticed a temperature adjustment reported that they exercised their option to override the temperature setting for comfort reasons. Homeowners commented that receiving a notification-before making an optimization set point change for energy savings-would be $\%$ of

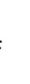

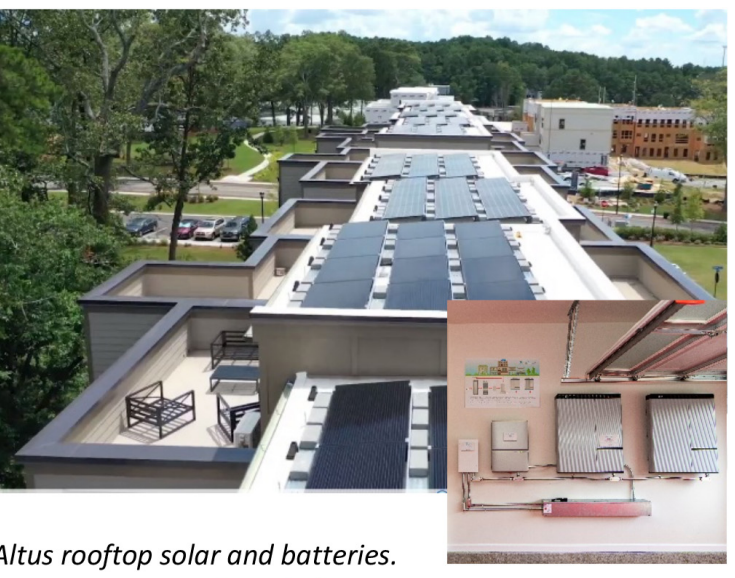

Images courtesy: Georgia Power. 


\section{Vendor Engagement}

Some residential appliance manufacturers offer branded suites of interoperable connected appliances with a common app for customer use. However, no readily available kit or interface seamlessly integrates various appliances with the HVAC, water heater, electric vehicle charger, and/or solar/battery equipment. For appliance manufacturers, offering an interoperable product line provides a sales advantage because builders often purchase a common package of appliances for installation in all homes within a new development.

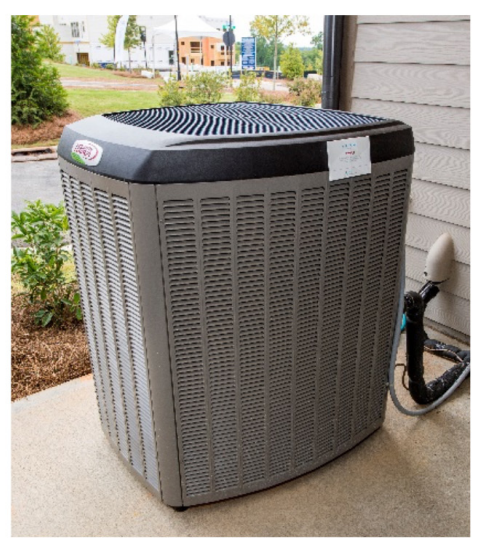

High-efficiency heat pump. Image courtesy: Georgia Power.
For both the Reynolds Landing and Altus neighborhoods, vendor participation was key to the success of the project. This includes manufacturers granting access to their Application Program Interface (API) to allow the Southern Company Residential Energy System to receive device data and pass along optimized device set points from ORNL's Oak Leaf home optimization and dispatch logic. The ORNL team coordinated closely with HVAC, water heater, thermostat, and inverter manufacturers to obtain information about their API, device data structure, and control parameters. This collaboration allowed the team to refine the optimization equations, coding, and dispatch control choices to suit each type and brand of equipment.

An example of successful vendor interaction is the inverter manufacturer for the solar photovoltaic systems installed at the Altus neighborhood. In this case, the ORNL team worked with the inverter manufacturer to understand their API, data structure, and control modes available through the API via the Modbus register. A hybrid approach using both the API and Modbus was used to allow information transfer and control dispatch.

Standardizing communication protocol, data framework, and allowable control modes/ranges would streamline this process from an ad hoc arrangement for every make/model of device to a consistent framework for each class of equipment - an example is shown in the hybrid heat pump water heater containing the CTA-2045 communications module. Further deployment of a standards based approach would greatly reduce development and implementation costs for GEB operation. It could also provide benefits to individual manufacturers, who could reduce their development and support costs needed for their current proprietary systems.

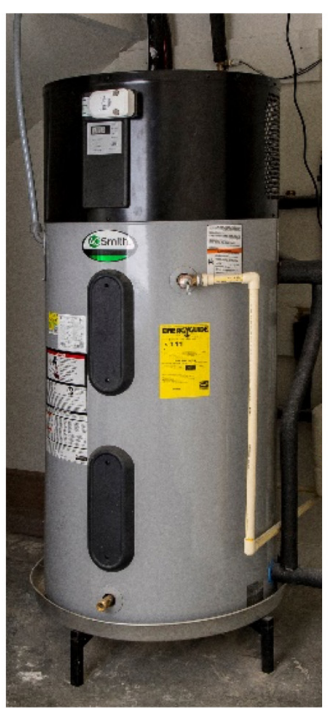




\section{Adoption by Utilities}

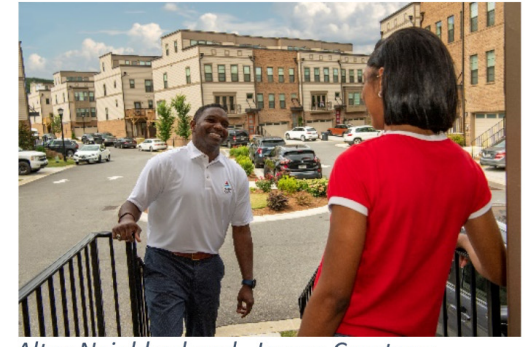

Altus Neighborhood. Image Courtesy: Georgia Power.

Funded by BTO, ORNL led a virtual workshop in September 2020 with utilities, third-party integrators, and industry consultants to review GEBs, share insights from GEB test cases, identify stakeholder viewpoints, and discuss challenges to GEB adoption at scale. Among the noted challenges were quantifying the value of GEBs both now and in the future (with increasing renewables in the generation portfolio), what implementation would cost, how reliable (e.g., "bankable") GEB benefits are, and how to integrate GEBs with existing energy efficiency and demand response programs. Participants indicated a strong interest in further GEB research and development. Stakeholders also noted that quantifying the value to customers is needed both in terms of energy cost savings as well as non-energy benefits such as improved experience (comfort and resilience). Understanding customer motivations, including interests outside of energy savings, was identified as important to increasing the uptake of smart energy-efficient home technologies and eventually GEBs. Participants agreed that more data is needed to prove the value of GEBs. Scaling up-from pilot-level assessments of residential communities to larger commercial building portfolios and campuses-will be key to proving the GEB opportunity.

\section{Learnings: Technical, Policy, and Business Model}

\section{Technical}

Home loads with the potential to provide the largest reductions in $\mathrm{CO}_{2}$ emissions using grid-interactive controls include water heaters, central air conditioners, air source heat pumps, pool pumps, and electric vehicle chargers.

Beneficial electrification of home loads (e.g., shifting from natural gas to electric cooking, water heating, and heating) will bring additional flexible loads into the residential portfolio.

To facilitate implementing grid-interactive controls both Advanced Metering Infrastructure (with its attendant smart meters, communications, and data management) and time-of-use tariff structures need to be in place. Advanced metering uptake has increased greatly since the rollout of the Smart Grid Investment Grant program, funded by the American Recovery and Reinvestment Act of 2009 and administered by the US Department of Energy. As of 2019, some 94 million smart meters were installed nationwide with almost $90 \%$ in residential installations. ${ }^{3}$ For time-of-use tariffs, the US Energy Information Administration 2019 Annual Electric Power Industry Report Dynamic Price File showed that just over 10 million customers across 700 utilities in the United States were using some form of a time-of-use tariff, and of those, $80 \%$ were residential customers. ${ }^{4}$ With both advanced metering infrastructure and time-of-use tariffs in place, utilities can work with customers to shift to time-of-use and adopt grid-interactive control of home loads such as the water heater and HVAC thermostats. Utilities such as Duke Power, Holy Cross Energy, Sacramento Municipal Utility District, and Southern Company's Alabama Power and Georgia Power have developed GEB demonstration projects to assess the potential for implementing GEBs across their systems. Research and development on communications, data framework/management, and load optimization models is needed to support implementation by third-party demand response integrators who can manage the communication and data management across the utilities' portfolio of customers.

\footnotetext{
3 “Frequently asked questions," US Energy Information Administration, 2020. [Online] Available at https://www.eia.gov/tools/faqs/faq.php?id=108\&t=3.

4 "Annual Electric Power Industry Report, Form EIA-861 detailed data files," US Energy Information Administration, 2020. [Online] Available at https://www.eia.gov/electricity/data/eia861/.
} 
Policy

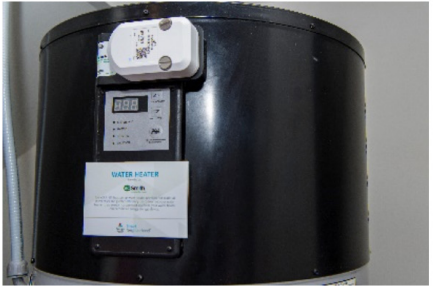

Water heater CTA-2045 module. Image courtesy: Georgia Power.
In addition to new technologies, policy could also help increase the adoption of grid-interactive smart home devices and systems for $\mathrm{CO}_{2}$ emission reductions. These advances could include state and federal rulemaking to identify performance criteria, reference standards, testing and certifications, and implementation dates. BTO's Appliance and Equipment Standards Program disseminates the regulations for appliance and equipment energy efficiency standards, including test procedures, certification, and enforcement. The US Environmental Protection Agency's voluntary ENERGY STAR and WaterSense programs address appliance and equipment features that provide energy efficiency benefits beyond the minimum standards. The ENERGY STAR program now includes smart devices such as thermostats, lights and switches that can be incorporated into an ENERGY START Smart Home Energy Management System (SHEMS).

At the state level, California, Washington, and Oregon have been active in developing state polices on grid-interactive appliances and equipment. In 2018, the Washington State Department of Commerce took action to update water heater standards to include aspects such as the adoption of the ANSI/CTA-2045 standard, as well as consumer privacy standards. Policy (rulemaking), codes, and standards actions can all help to standardize device connectivity technology, lower associated hardware and support costs, and move toward interconnectivity between various appliance types and manufacturer makes/models.

\section{Business Model - Smart Home Devices}

Home equipment and appliances only began to feature internet connectivity fairly recently. In a commodity market, appliance and equipment manufacturers likely cannot increase device prices enough to cover the required communications and data support necessary for the 12 to 20 year life of a typical appliance. However, manufacturers can move beyond offsetting the added cost of loT functionality by creating new value from loT-derived data streams. This added value can be generated by using data to inform product enhancements, marketing the data itself as a separate product, optimizing manufacturing processes, improving customer service, and creating new customer experiences. These approaches of using data to add value to the primary equipment and appliances are logical next steps as manufacturers explore loT benefits.

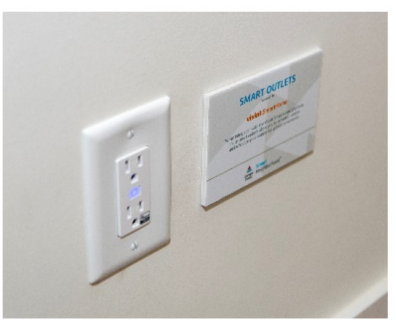

Altus Home Smart Receptacles. Image Courtesy: Georgia Power.

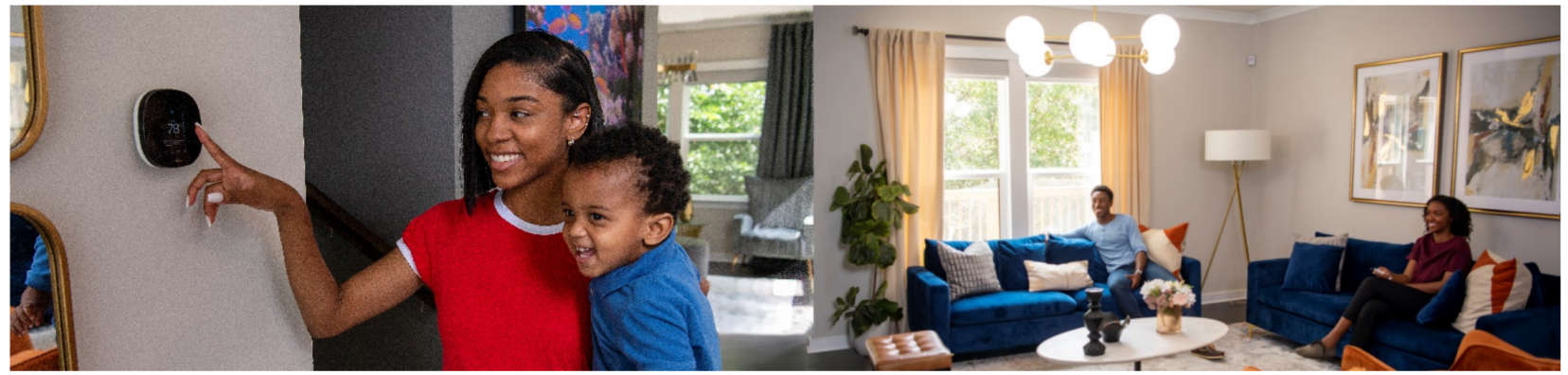

Altus homeowners. Image Courtesy Georgia Power. 
Southeastern Focus Place-Based Technology Innovation Summit 
